
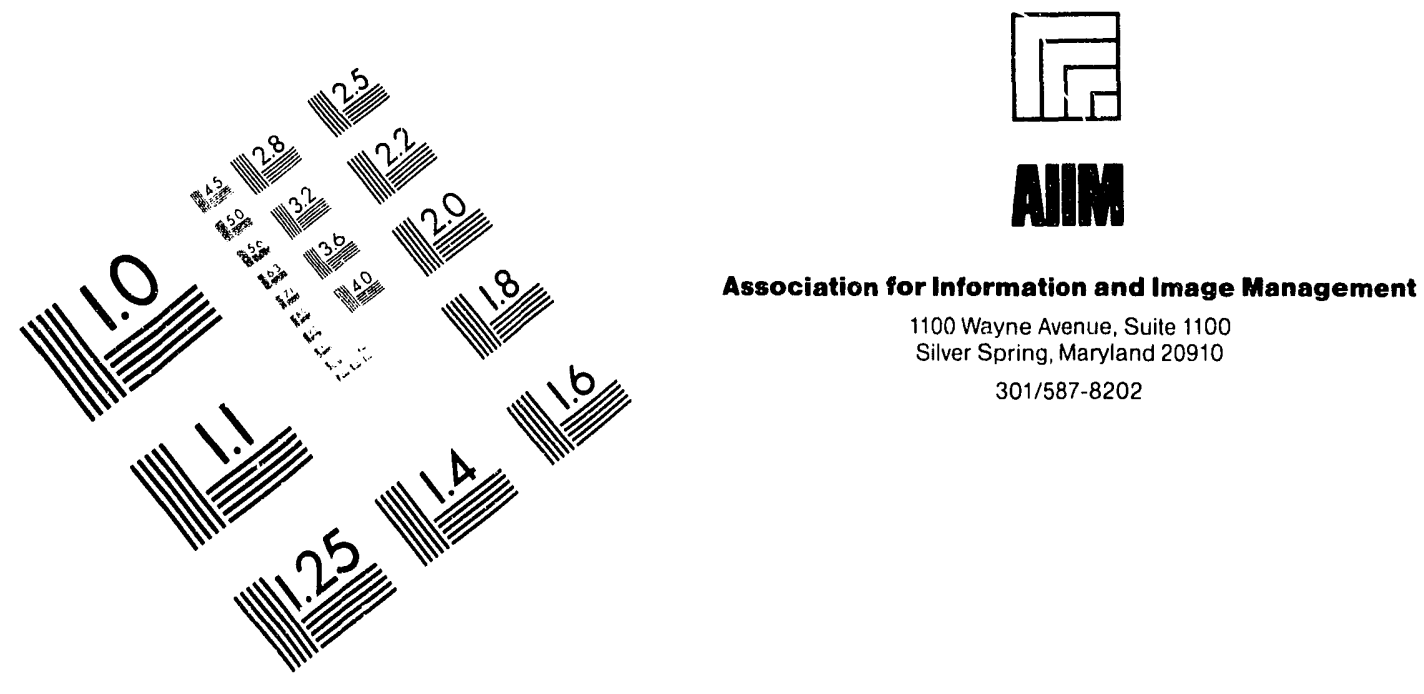

1100 Wayne Avenue, Suite 1100

Silver Spring, Maryland 20910

301/587-8202

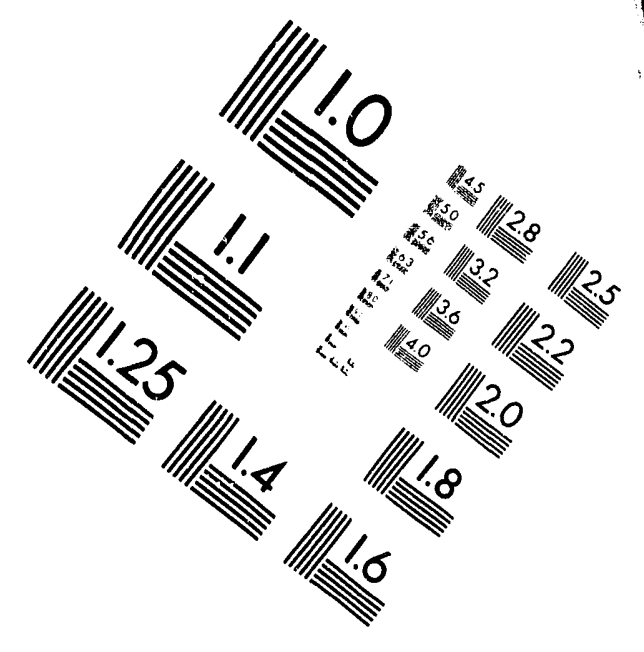

Centimeter

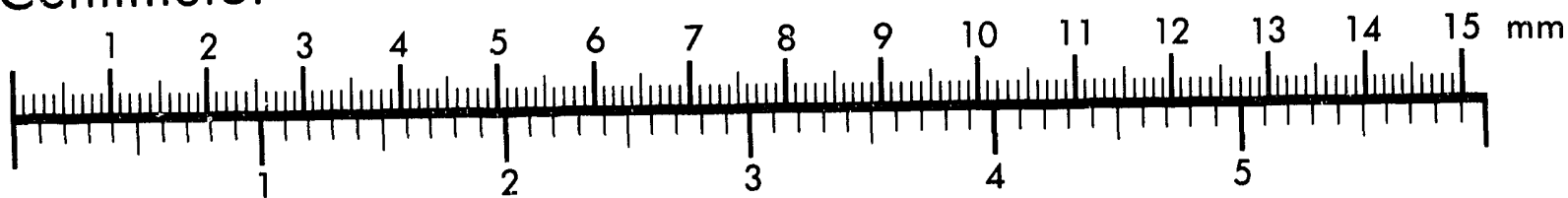
Inches
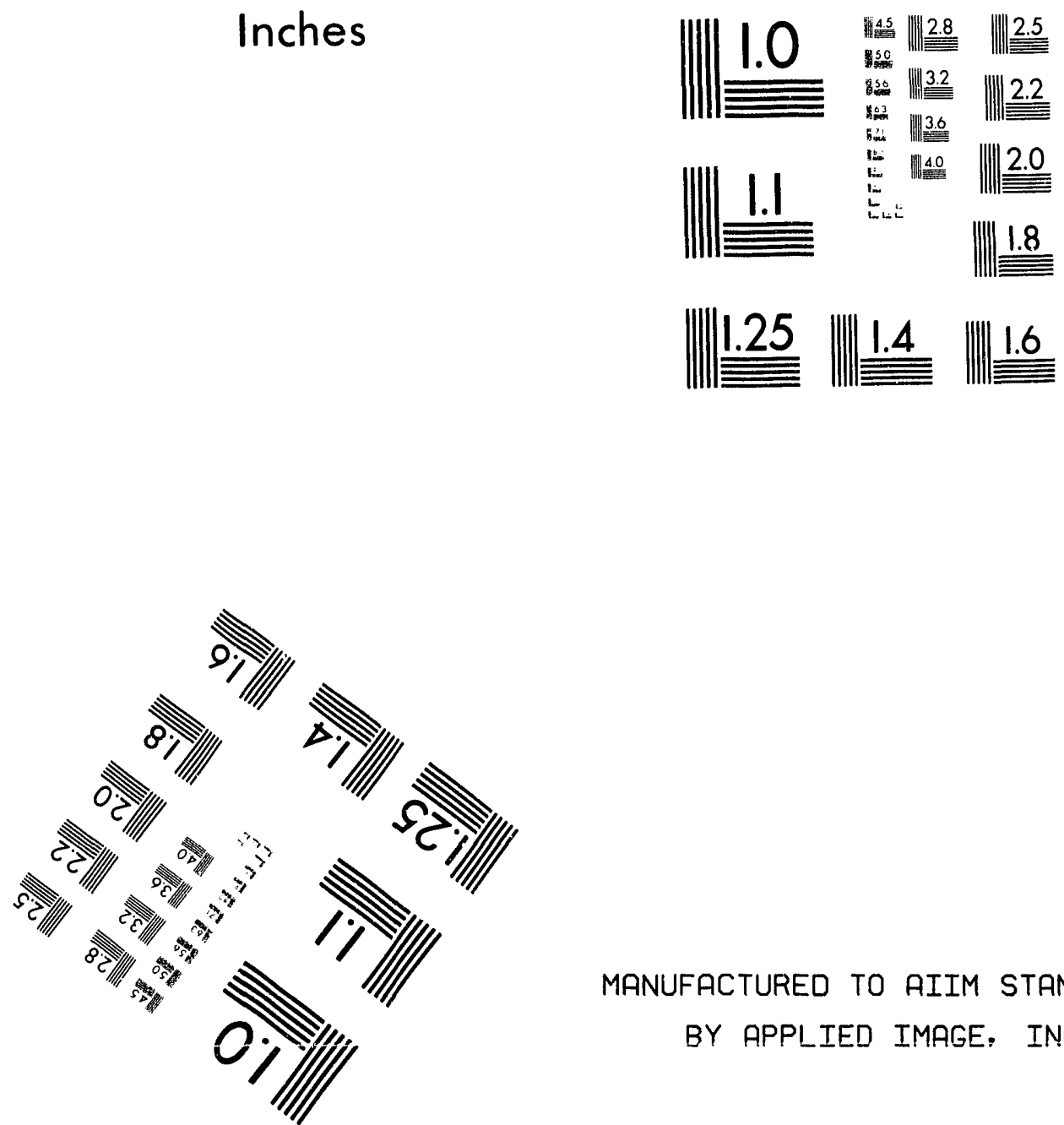

MANUFACTURED TO AIIM STANDARDS

BY APPLIED IMAGE, INC.

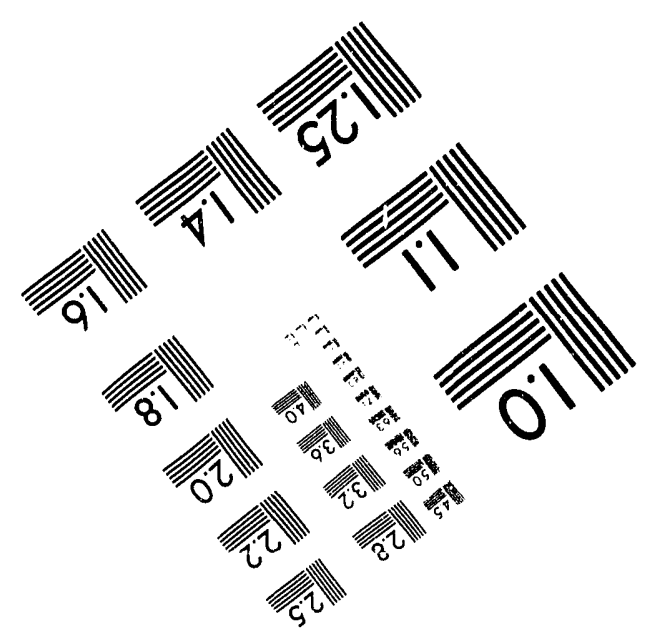



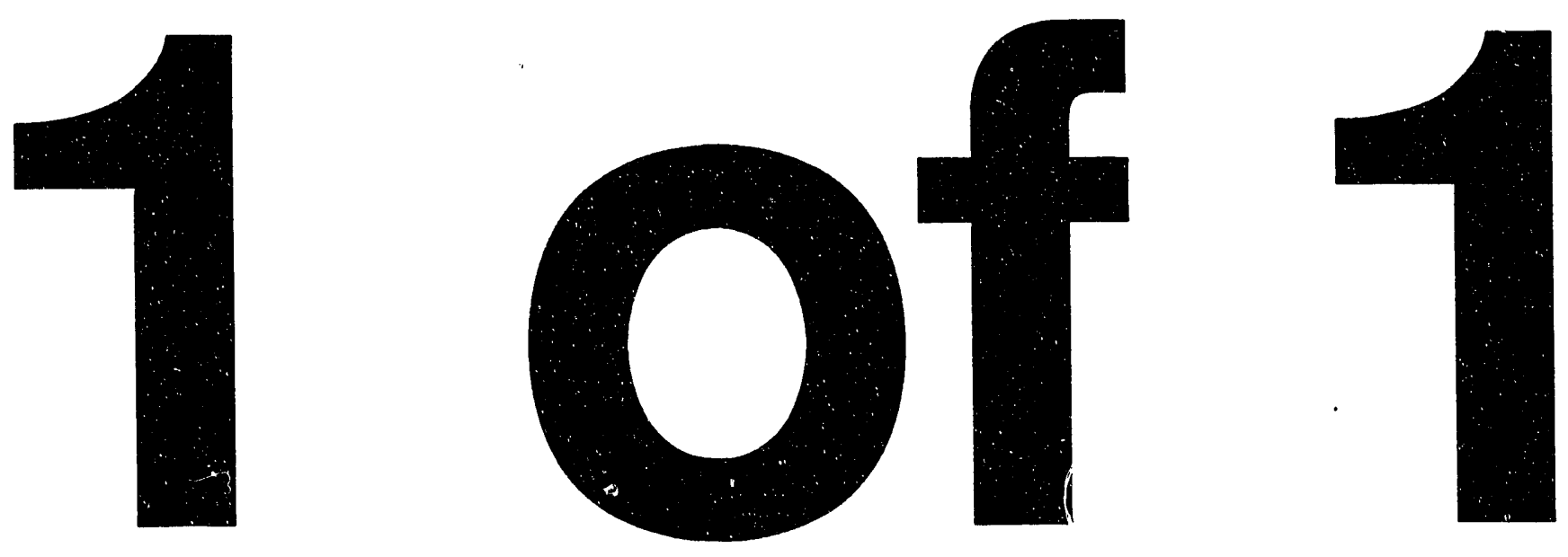
SAND 93-0910

Distribution

Unlimited Release

Printed May, 1993

Category UC-706

\title{
EVALUATION OF MIDBAND ANALOG FIBER OPTIC TELEMETRY IINRS
}

\author{
Gordon J. Hansen \\ Dept. 9322
}

Sandia National Laboratories

Albuquerque, NM 87185

\begin{abstract}
AB8TRACT
Midband ( $1 \mathrm{KHz}-500 \mathrm{MHz}$ ) analog fiber optic data links were purchased for evaluation from three suppliers. Ortel Corp., Alhambra, CA., provided units built to our specifications. Kaman Sciences Corp, Colorado Springs, Co. and Laser Diode Inc., Princeton, NJ, provided units similar to our specification but with significant differences. The final version of the ortel units met our specification but were marginal in dynamic range. The other units failed to meet our specification but showed promise for future application.
\end{abstract}

\section{MASTER}

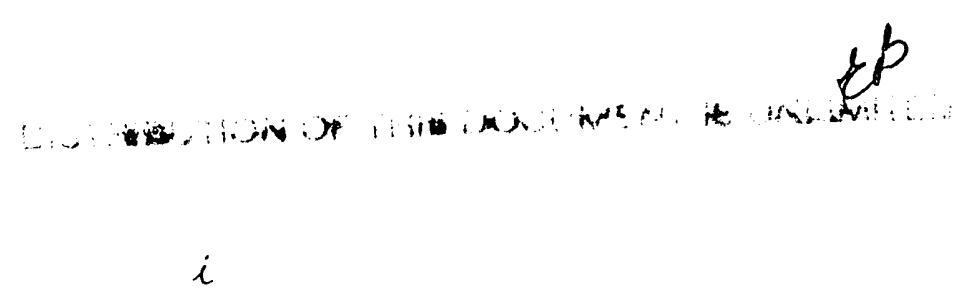




\section{CONTENTS}

Evaluation of Ortel Model 5522 Analog Fiber Optic Link.... 1

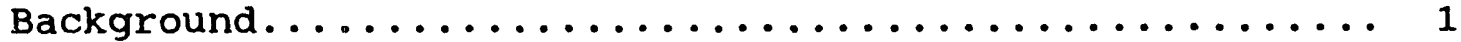

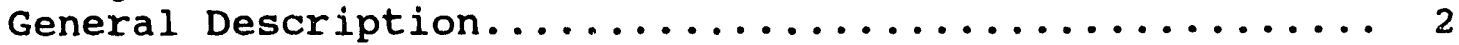

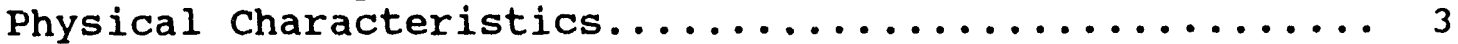

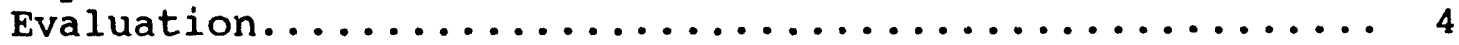

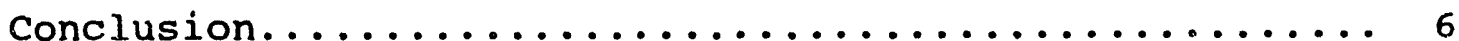

Figures

1. Ortel Model 5522 Transmitter Rear Panel............ 7

2. Ortel Model 5522 Receiver Rear Panel............... 8

3. Response and Attenuation of Ortel. 5522 Link.......... 9

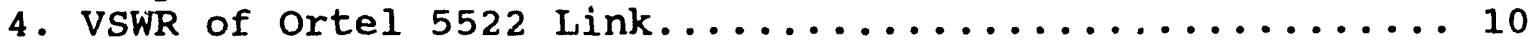

5. Linearity Plot for ortel 5522 Link............... 11

6. Input/Output overlay for ortel 5522 Link............ 12

7. Link Noise at $-40 \mathrm{~dB}$ for ortel 5522 Link............. 13

8. HUNTERS TROPHY Lasercal Factors for ortel Links....... 14

APPENDIX A - Specification for Fiber Optic Telemetry Link.. 15

APPENDIX B - Evaluation of Kaman Sciences KPL100 Link..... 18

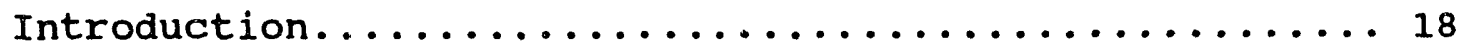

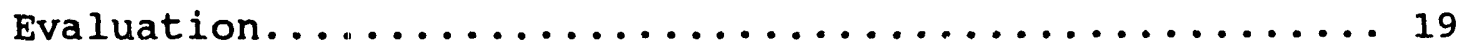

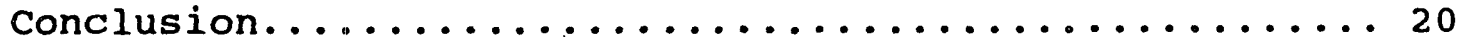

Figures

1. Response, Attenuation and VSWR for KSC Link......21

2. Linearity Plot for KSC KPL100 Link............. 22

3. Input/Output Overlay for KSC KPL100 Link........ 23

4. Link Noise at $-34 \mathrm{~dB}$ for KSC KPL100 Link.......... 24

APPENDIX B-1 - Description of KSC KPL100 Link........ 25 APPENDIX B-2 - Specification for KSC KPL100 Link...... 29

APPENDIX C - Evaluation of Laser Diode Inc LDAT2200 Link... 31

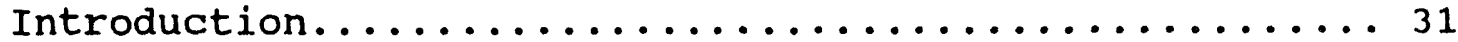

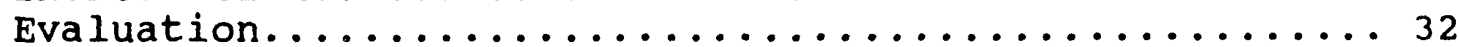

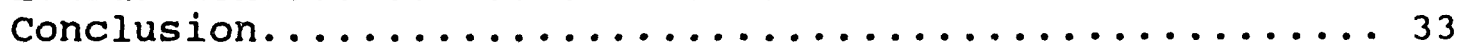

Figures

1. Response and Attenuation of LDI LDAT2200 Link.... 34

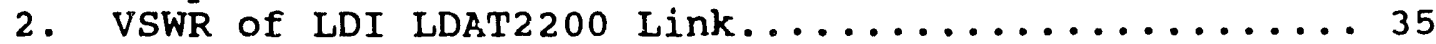

3. Linearity Plot for LDI LDAT2200 Link........... 36

4. Input/Output Overlay for LDI LDAT2200 Link...... 37

5. Link Noise at $-40 \mathrm{~dB}$ for LDI LDAT 2200 Link....... 38

APPENDIX C-1 - Description of LDI LDAT2200 Link...... 39 
EVALUATION OF ORTEL MODEL 5522 ANALOG FIBER OPTIC LINK

\section{BACKGROUND}

After several years experience using wideband analog fiber optic links from various manufacturers, it became obvious that although the newer links worked quite well, the cost $(\$ 8,000+$ per link) was a limiting factor in their use. In addition, the bandwidth of the links ( 2 to $3 \mathrm{GHz}$ ) was greater than that required for most measurements. The decision by DNA to procure Tektronix RTD720 digitizers (500 MHz response) and the desire to extend the low frequency response of the links to less than $10 \mathrm{KHz}$ led to the decision to obtain a "low cost" midband link ( $1 \mathrm{KHz}$ to 500 $\mathrm{MHz}$ ) .

Discussions with experimenters, recording specialists and potential suppliers, and consideration of our own experiences, led to the development of a specification (Appendix A) which was placed for bid in october 1991. ortel Corp., Alhamkra, Ca. was the only responsive bidder, so an order was placed in November 1991 for ten units. Two other companies, Kaman Sciences Corp. and Laser Diode Inc., offered units which did not completely meet our specification. However, two evaluation links were ordered from each of these alternate suppliers. Neither of them was able to deliver in time to support DNA measurements on the HUNTERS TROPHY Event at the Nevada Test site. The units from Laser Diode Inc. were installed on a Sandia Laboratory add-on experiment without undergoing the normal checkout procedures. The Kaman Sciences units were not received until after HUNTERS TROPHY. Results of the evaluations on those links are included as Appendix B for the KSC units and Appendix $C$ for the Laser Diode units. 
Prototype links from ortel were evaluated (and rejected) on several occasions between February and June, 1992. Major problems were marginal frequency response, poor linearity and unacceptable dynamic range. In mid June, 1992, the "final" units were delivered. None met the specified dynamic range. Due to the desire to field them on the HUNTERS TROPHY Event, seven units were conditionally accepted. Three units were returned for further rework (a new, lower noise amplifier) with the understanding that the other seven would be returned after the event. In late July, the three reworked units were received and found to meet the major specifications.

The ten units were fielded in support of the SAIC system \#1 measurements on HUNTERS TROPHY. All links transmitted useful data, although some were noisier than desired (as expected). After the event, the seven unmodified links were returned to ortel corp. They are currently (January, 1993) being reworked. The data presented in this report are based on measurements made on the three units which met specifications. Data from the other units is very similar with the exception of dynamic range.

\section{GENERAL DESCRIPTION}

The ORTEL Model 5522 analog fiber optic link is designed to transmit midband ( $1 \mathrm{kHz}$ to $500 \mathrm{MHz}$ ) unipolar or bipolar transient data over greater than 7 kilometers of low loss 1300 nanometer singlemode optical fiber. The link consists of a small low power laser transmitter and mating receiver.

The transmitter is based on ortel's Indium-GalliumArsenide-Phosphide solid-state laser technology. It uses a distributed feedback (DFB) laser for stability and narrow line width, but is uncooled to reduce costs and power 
consumption. To provide acceptable gain stability with temperature, it uses an out-of-band (800 MHz) AGC reference carrier to compensate for link drift. It also contains a pulse calibrator to allow late time link calibration. It is switchable to allow either Unipolar or Bipolar operation.

The receiver contains a high stability photodiode module coupled to a multistage amplifier which is gain controlled by the reference carrier from the transmitter. It also contains an equalization network to compensate for link characteristics.

\section{PHYSICAL CHARACTERISTICS}

Both transmitter and receiver are packaged in small $3.0 \times 4.0 \times 1.5$ inch modules with all optical and electrical connections on the end opposite the mounting flange. Fig. 1 is an outline drawing of the transmitter module with connector pinouts shown. Fig. 2 is an outline drawing of the receiver with its connector pinouts.

Ten transmitter modules were mounted in a standard 19 inch rack mountable chassis 5.25 inches high by 24.0 inches deep. The modules were mounted on a large finned heat sink to ensure temperature stability and powered by redundant power supplies. Laser bias current and photo current were metered on the front panel. Signal inputs were provided on the rear panel utilizing type ' $N$ ' connectors. Optical fiber connection was via welded pigtails.

Ten receiver modules were mounted in a similar chassis (without the heat sink) and also redundantly powered. optical and electrical inputs were accomplished identically as those for the transmitters. Receiver photo current was metered on the front panel. 


\section{EVALUATION}

The coupled links were subjected to the same suite of test procedures used to characterize the links used on previous events. They consist of measurements of bandwidth, attenuation, input standing wave ratio (VSWR), linearity and dynamic range. Also input/output overlays are generated to check for any pulse anomalies such as overshoot, undershoot, pulse tailing, ringing, droop or other distortions.

Figure 3 is a network analyzer plot of the response (bandwidth) of a typical model 5522 ortel link. The specification calls for a flat response $(+/-0.5 \mathrm{~dB})$ from 1 $\mathrm{KHz}$ to $500 \mathrm{MHz}$. The plot indicates that the link meets that specification. This same plot also shows the link attenuation to be nominally $18 \mathrm{~dB}$. The specification requires less than $20 \mathrm{~dB}$. Performance in both areas is within specification.

Figure 4 is a network analyzer plot of VSWR versus frequency and is also typical of all of the 5522 links. The values range from 1.22 over most of the range of interest to approximately 1.5 at the frequency extremes. This corresponds to a return loss of between 14 and $20 \mathrm{~dB}$ as compared with the specified $15 \mathrm{~dB}$ or greater.

Figure 5 is a plot of linearity, taken as typical for all units. This plot shows the actual output versus input voltage overlaid with a fitted linear ideal. The specification calls for a maximum deviation of $+/-5 \%$ from a straight line fitted to the data. The unit is well within that specification.

Figure 6 is an oscilloscope photograph of an input pulse superimposed on an output pulse after passage through the link. As can be seen, the difference in wave shape is 
negligible. Risetime, top-pulse linearity, fall time and return to baseline, track almost perfectly.

Figure 7 is an oscilloscope photograph showing a multiple exposure of a full scale signal attenuated by $40 \mathrm{~dB}$ (20mV applied to the transmitter) and the associated link noise. This shows the signal-to-noise ratio at this input level to be approximately unity, which corresponds to a link dynamic range of $40 \mathrm{~dB}(100: 1)$. Although meeting specification, it is certainly much noisier than desired. Previous links (Ortel model 5520 and 5521), although having dynamic range specifications of $40 \mathrm{~dB}$, typically measured 46 to $60 \mathrm{~dB}$. Specification for additional midband units will call out a dynamic range of at least $46 \mathrm{~dB}$ to be more in line with the dynamic range of an 8 bit digitizer (256:1).

Figure 8 summarizes lasercal data taken on HUNTERS TROPHY dry runs over the period of several weeks. Gain trends for all of the DNA fiber optic links are shown. The ortel 5522 links were used to support the SAIC system 1 measurements. Looking at the last column ( 8 standard Deviation) it can be seen that the ortel 5520 and 5521 links typically show a deviation of less than $1 \%$ while the 5522 links average about 3.5\%. Much of this difference may be attributed to the phenomenon seen on previous events where it was noted that new links apparently undergo a burn-in process. Link gain changes several percent during the first month of operation and then tends to level out for the remainder of the life of the laser. The 5520 and 5521 links had all been used on previous events and had stabilized out, while the 5522 links were new on this event. However, it will be necessary to carefully monitor the 5522 links on future events to determine if they stabilize out or if they 
continue to show greater gain deviation than the older links.

\section{CONCLUSION}

Ten Ortel model 5522 midband fiber optic links were successfully fielded on the HUNTERS TROPHY Event. In spite of higher than desired noise levels, all yielded usable data. Several product improvements (dynamic range and stability) have been requested from the suppliers and it is expected that future units will completely meet requirements. 

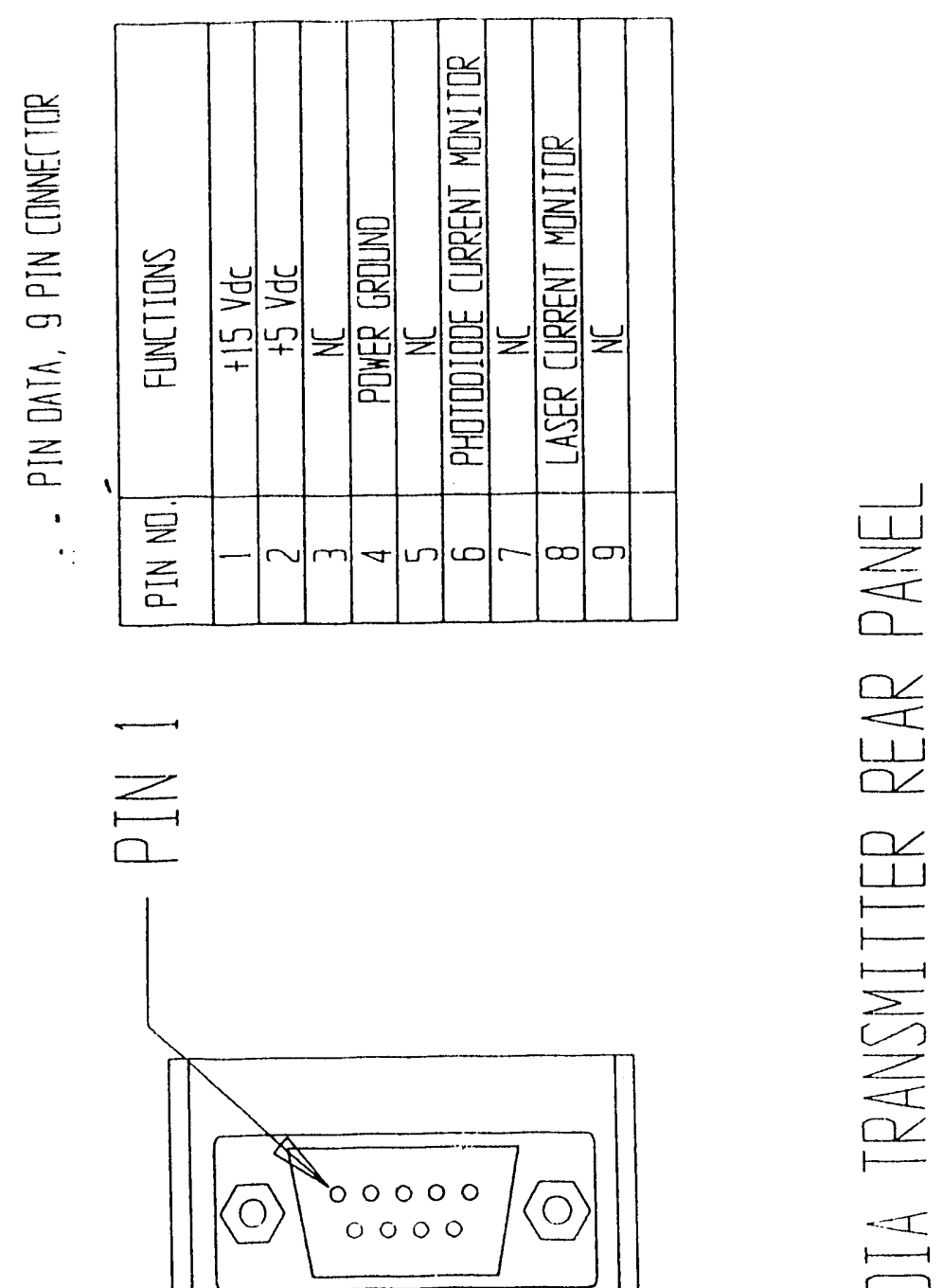

0

$\sum_{\infty}^{\infty 1}$

Fig. 1. Ortel Model 5522 Transmitter Rear Panel 

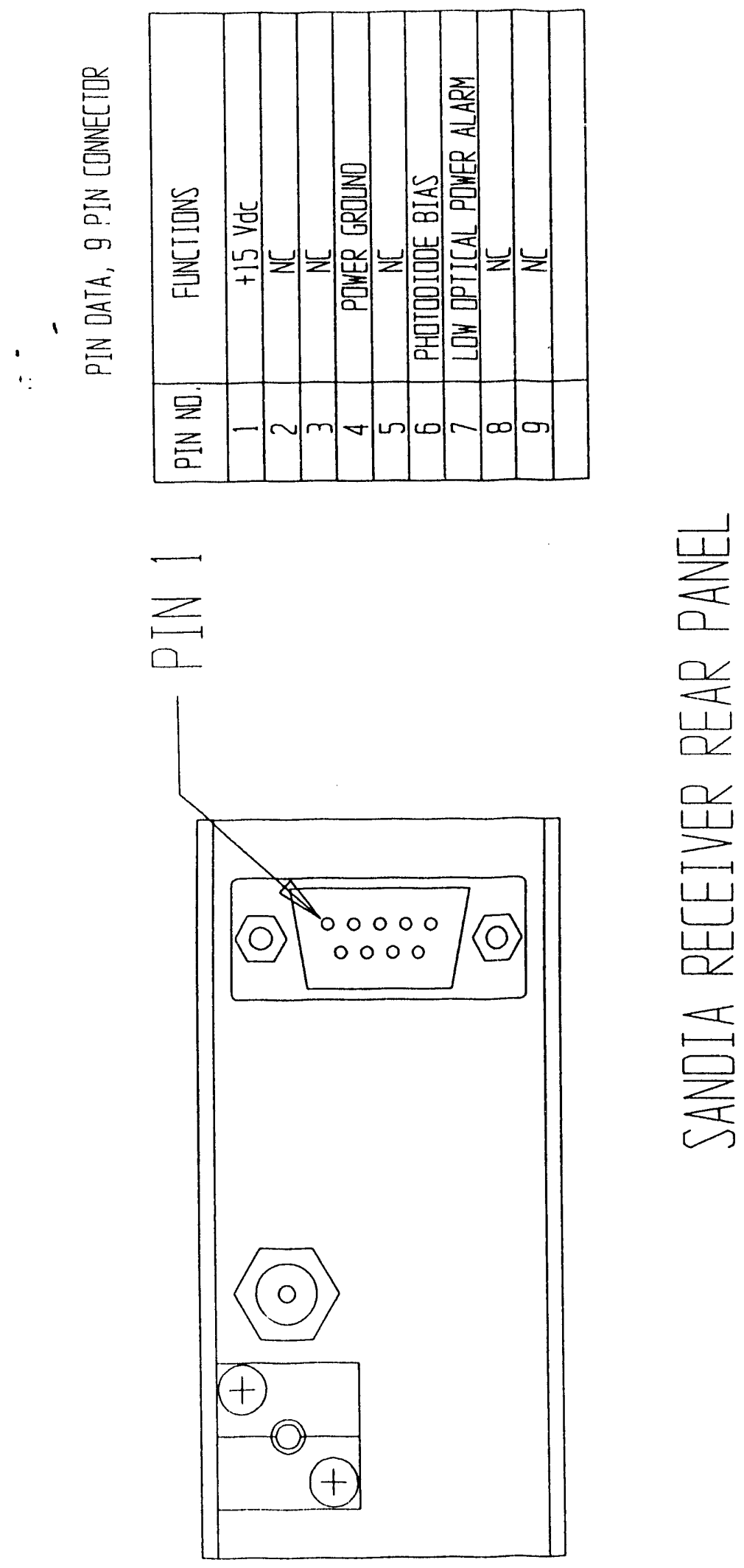

Fig. 2. Ortel Model 5522 Receiver Rear Panel 


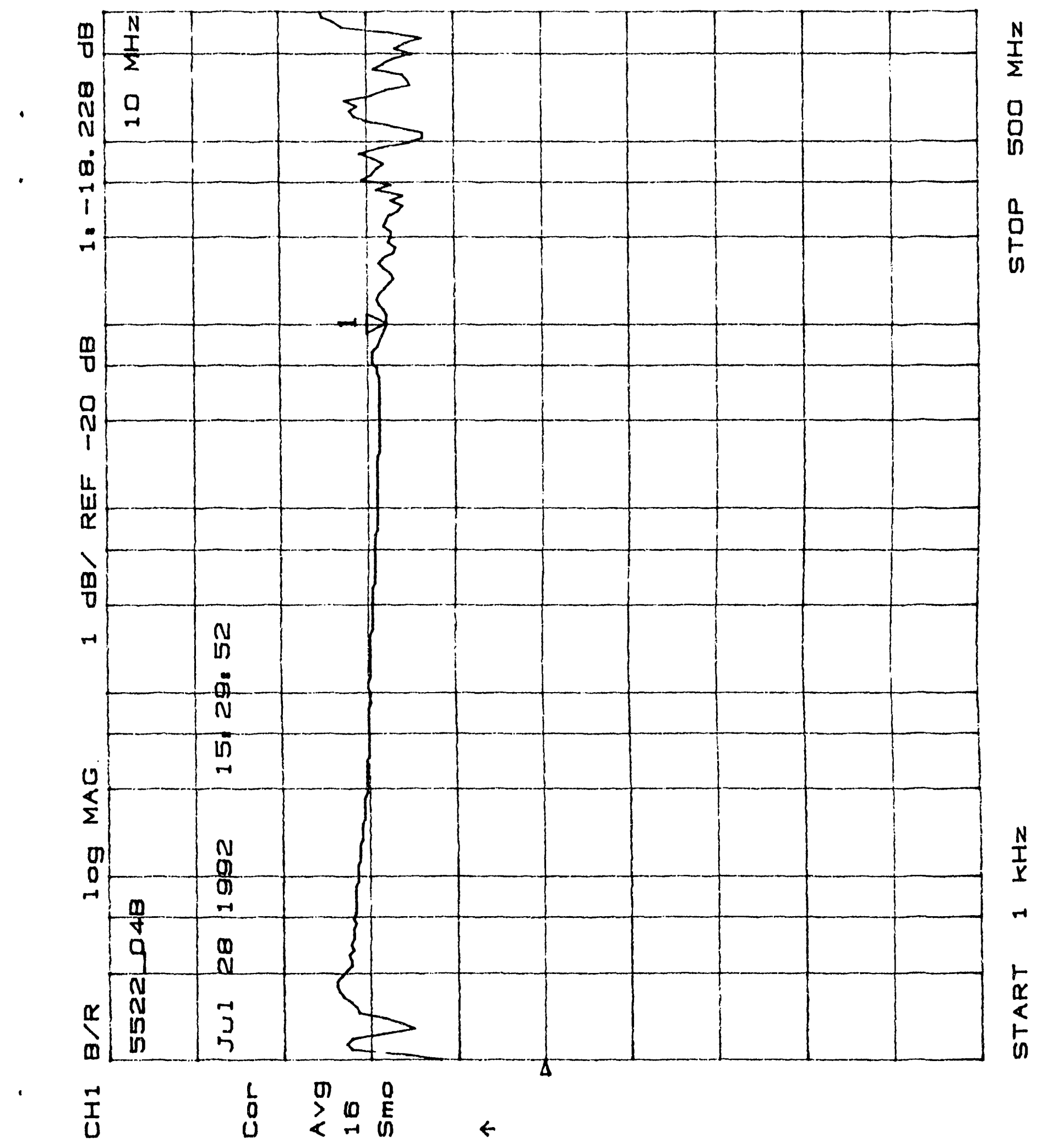

Fig. 3. Response and Attenuation of Ortel 5522 Link 


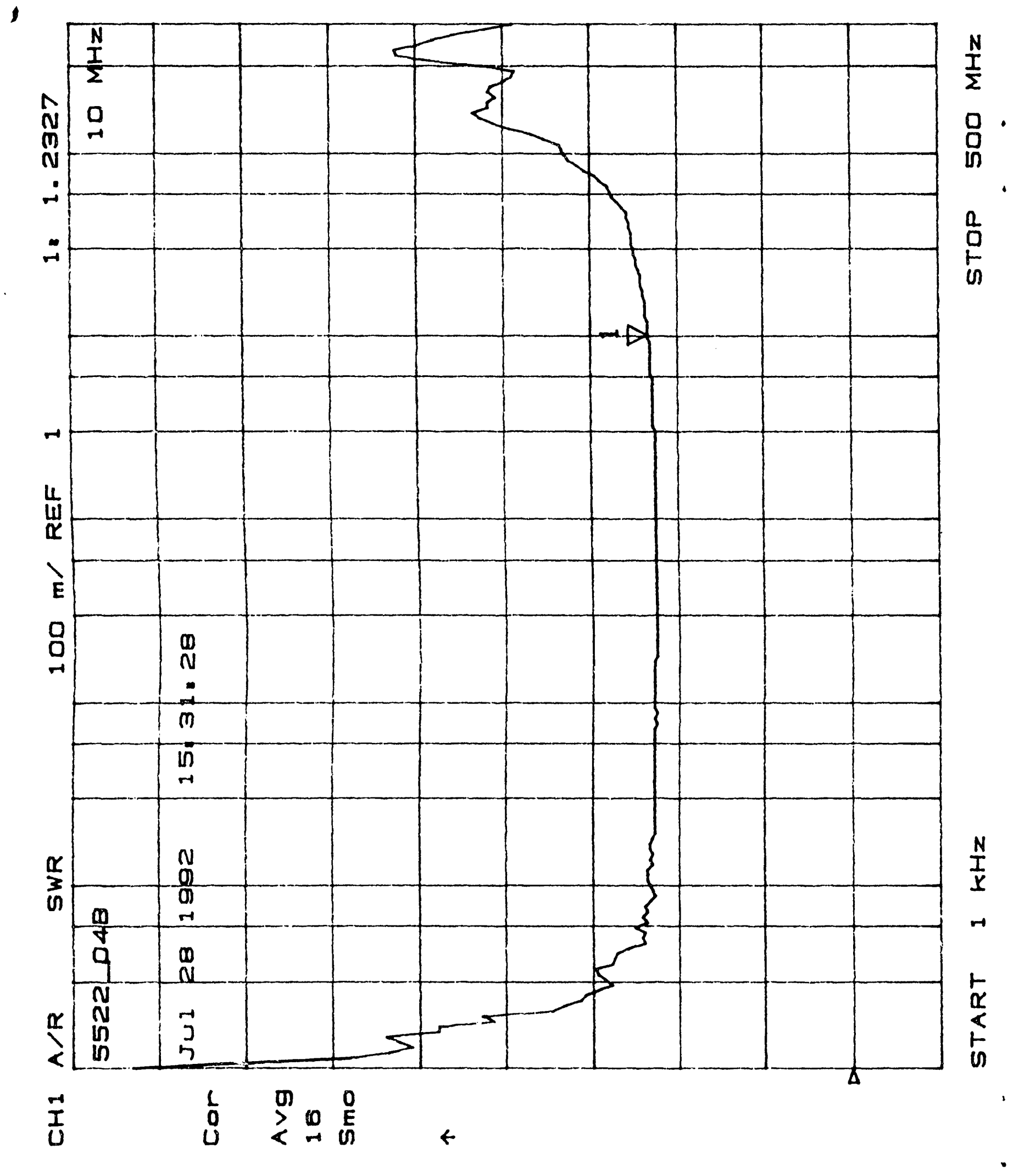

Fig. 4. viswe of ortel 5522 Link 


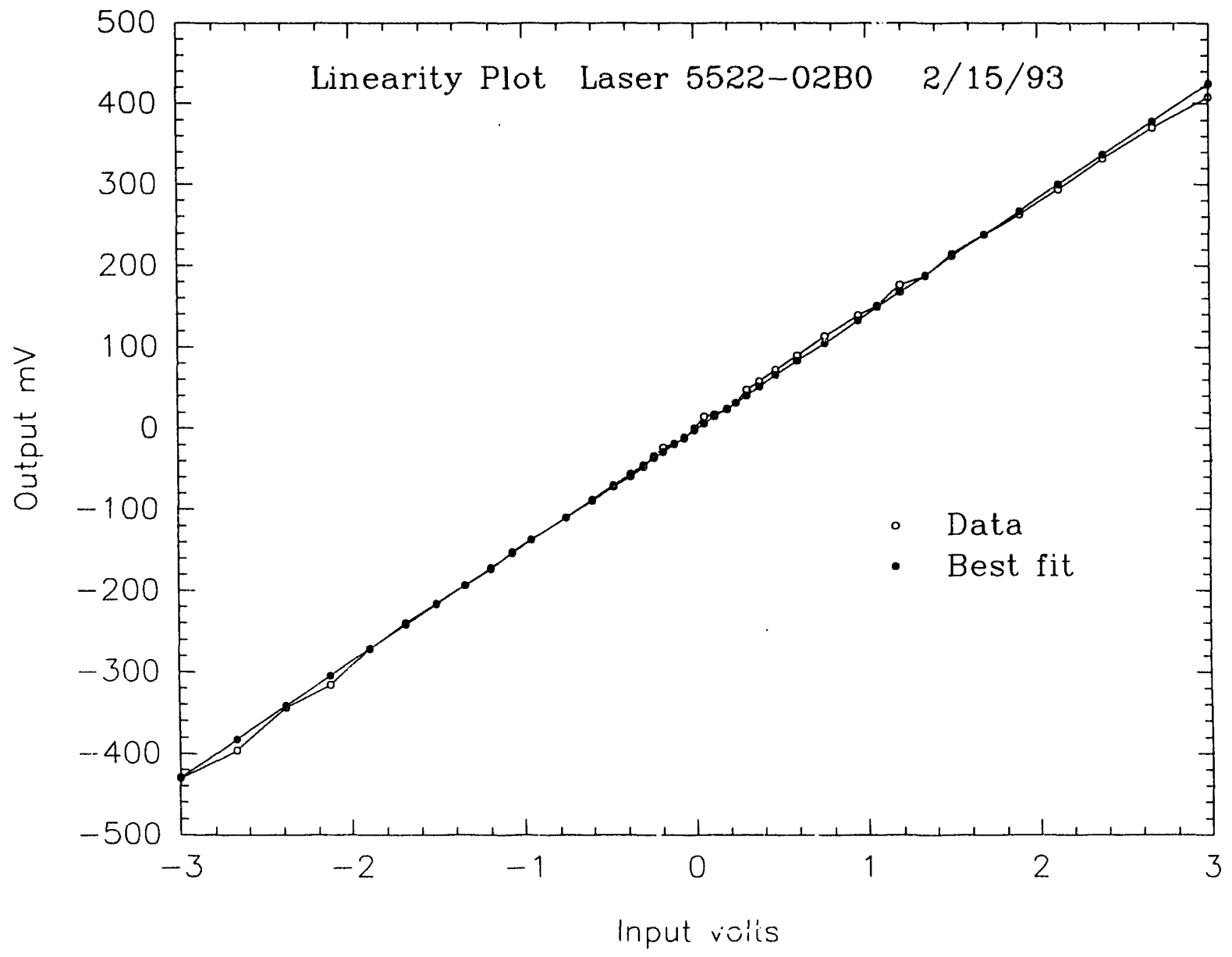

Fig, 5. Linearity Plot for ortel 5522 Link (11) 


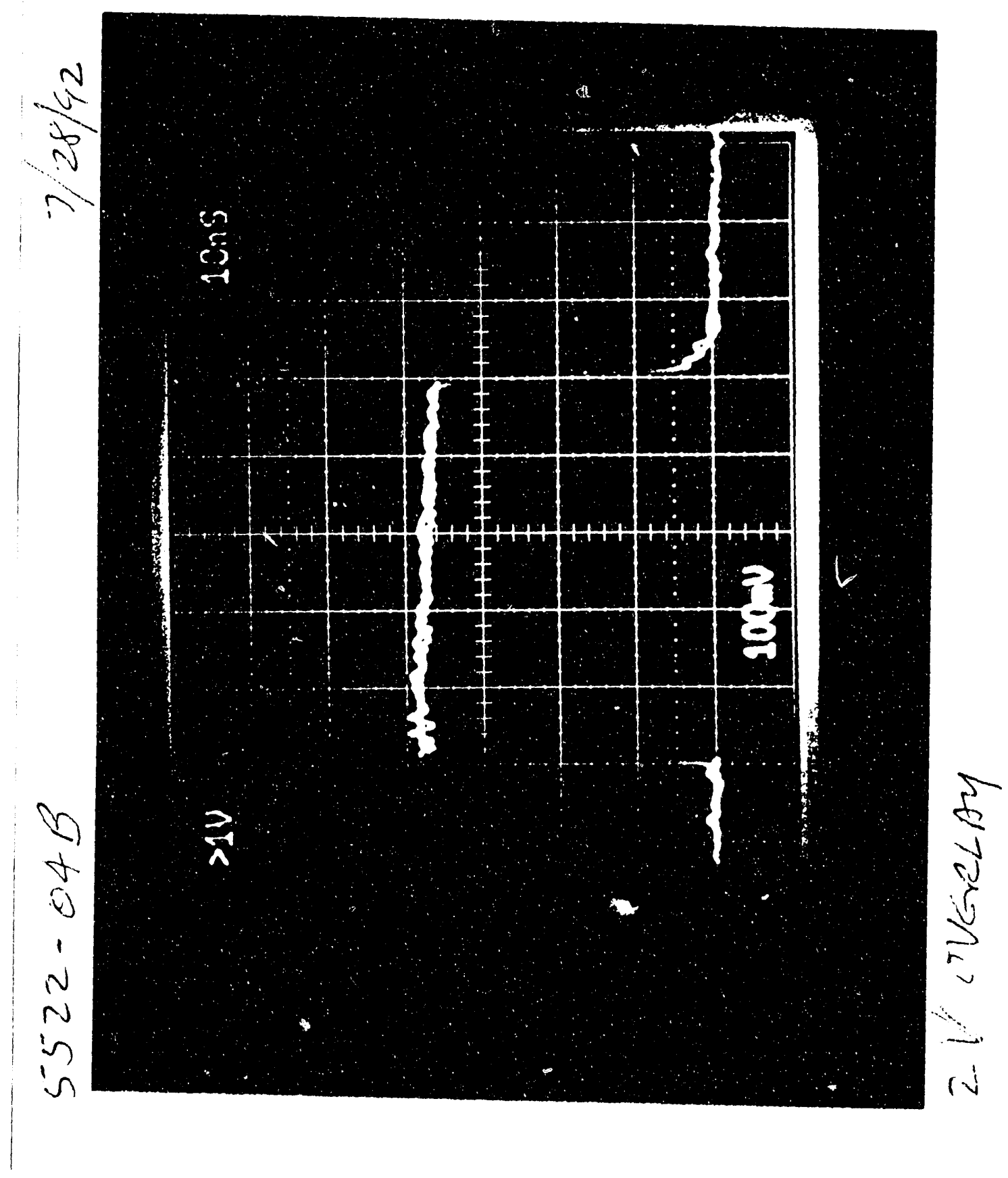

Fig. 6. Input/Output overlay for ortel 5522 Link 


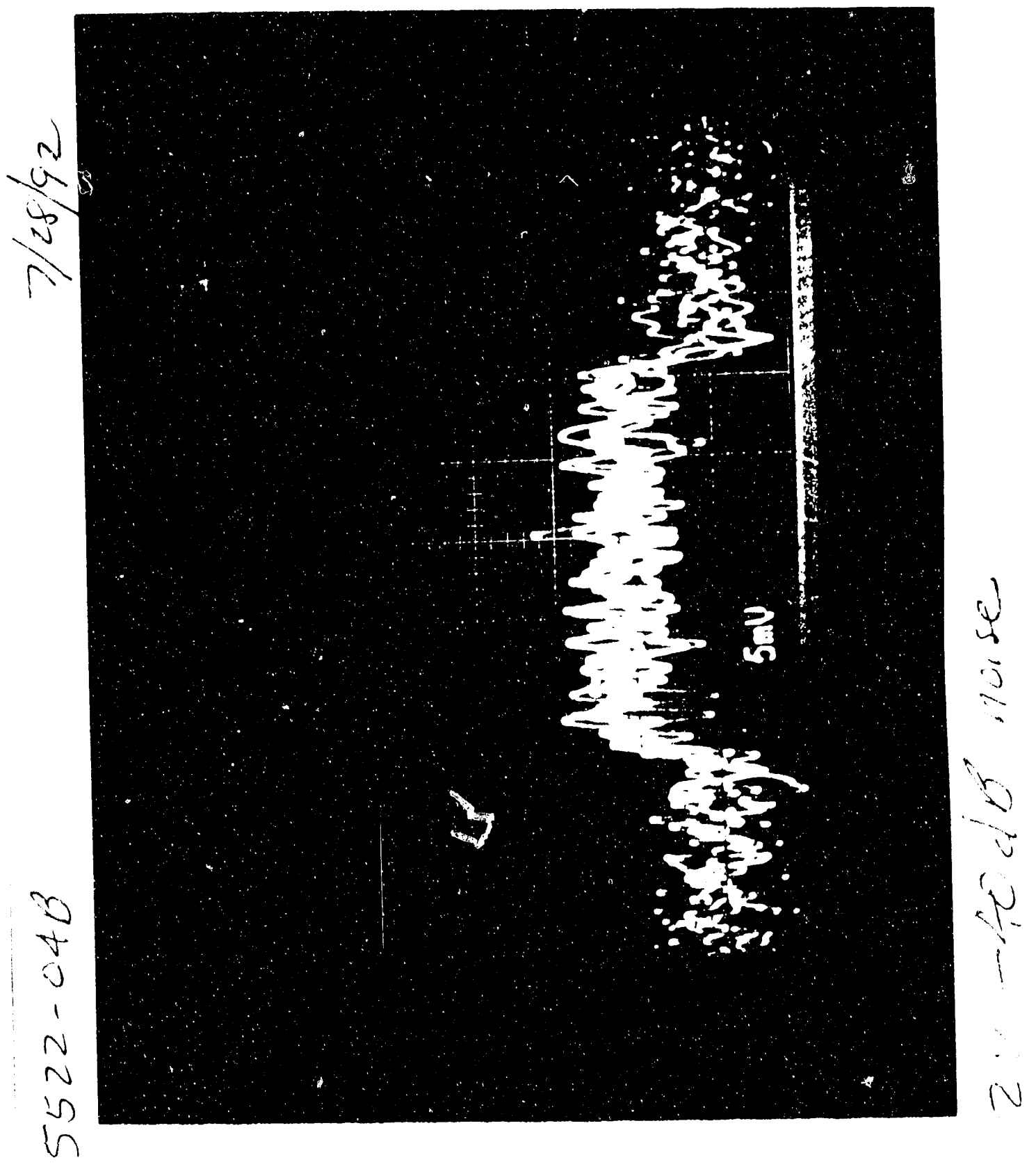

Fig. 7. Link Noise at $-40 \mathrm{~dB}$ for ortel 5522 Link 
HUNTERS TROPHY DNA EXperiments Laser Cal Factors fo Xmitter to Recorder

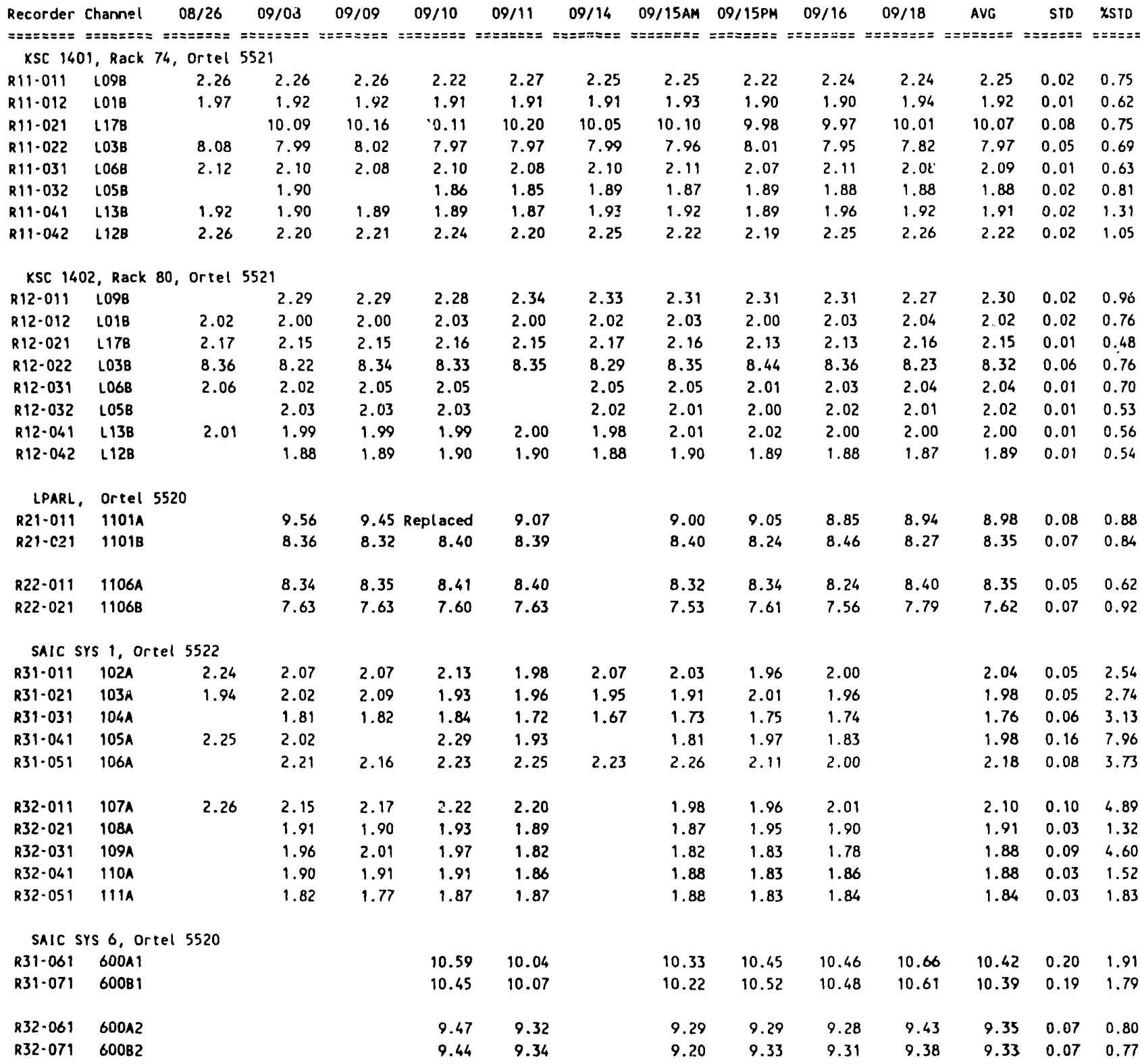

Fig. 8. Hunters Trophy Lasercal Factors for ortel Links 


\section{APPENDIX A}

\section{SPECIFICATION FOR A WIDEBAND \\ ANALOG FIBER OPTIC TELEMETRY LINK}

This analog fiber optic link is for transmitting high speed unipolar or bipolar transient data over greater than $7 \mathrm{~km}$ of low loss 1310 nanometer singlemode optical fiber. The link consists of a small low power laser transmitter and mating receiver.

\section{Link Specification}

Link Length:

Link Loss:

Frequency Response:

Pulse Response:

Linearity:

Dynamic Range:
$7 \mathrm{Km}$ typical

Less than $20 \mathrm{~dB} \quad(10: 1)$ non-inverting electrical input to output.

Link gain shall be adjustable to allow gain standardization between links.

$1 \mathrm{KHz}$ to $500 \mathrm{MHz}$

flat to $+/-0.5 \mathrm{~dB}$

Response to a step-like input of $<200$ ps first transition duration shall be:

Risetime $<800$ ps Overshoot $<5 \%$ Preshoot $<2 \%$ Droop < $5 \%$ in 50 microseconds maintained over the dynamic range.

$+/-5 \%$ for all frequencies in the pass band. Linearity is defined as the maximum deviation from a straight line best fit to the system gain, measured with a pulsed signal over the dynamic range of the link.

Greater than $40 \mathrm{~dB}(100: 1)$ as defined by: $\mathrm{DR}=\mathrm{V}$ peak / $(3 \star \mathrm{V}$ noise $\mathrm{rms})$

where $V$ peak is the peak output voltage at which the linearity specification can be met, and $V$ noise rms is the measured rms output noise voltage, integrated over the passband. 
Stability:

Calibration:

Operating Environment:

Storage Environment:

Lifetime:
For the environmental conditions stated, the link gain shall be stable to $+/-1 \mathrm{~dB}$.

For a transmitter case temperature stable to $+/-2$ degrees $C$, within a range of 15 to 40 degrees $C$, and a receiver case temperature stable to $+/-5$ degrees $c$, within a range of 15 to 30 degrees $C$, the link stability shall be:

$$
\begin{array}{ll}
\text { short term }(1 \mathrm{hr}) & +/-0.1 \mathrm{~dB} \\
\text { long term }(48 \mathrm{hr}) & +/-0.4 \mathrm{~dB}
\end{array}
$$

The link shall have a built-in calibration pulse generator to allow link gain to be determined to within $+/-1.0 \%$. This signal shall consist of a step-like pulse with the following specifications:

Amplitude: 1.00 volt $+/-1.0 \%$

width: 100 ns nominal

Risetime: $<1.0 \mathrm{~ns}$

Overshoot: $<3.0 \%$

Droop: $\quad<1.0 \%$

Delay: <10 ns (trig in to pulse out)

This pulse shall be applied to the input of

the transmitter upon application of a trigger

pulse from an external source with the following specifications:

Amplitude: 3 to 15 volts into 50 ohms Width: $>50$ ns

Risetime: $<10$ ns

The transmitter unit must operate and maintain specification over the following conditions: Temperature: 0 to 50 degrees $C$ Humidity: $\quad 0$ to $90 \%$, non-condensing

The receiver unit must operate and maintain specification over the following conditions: Temperature: 15 to 35 degrees $C$ Humidity: $\quad 0$ to $90 \%$, non-condensing

The link must operate within specifications after storage under the following conditions: Temperature: $\quad-40$ to 70 degrees $C$ Humidity: $\quad 0$ to $99 \%$, non-condensing

The link shall meet specifications over an operational lifetime of $>5000$ hours. 


\section{TRANSMITTER SPECIFICATION}

Optical Wavelength: Coupling Efficiency:

$1310 \mathrm{~nm}+/-30 \mathrm{~nm}$

Output Power:

Fiber Type:

Connection:

Input Voltage:

Input Protection:

Input Impedance:

Input Connector:

Cal trigger input:

Power Requirements:

Monitors:

$>.01 \mathrm{~mW} / \mathrm{mA}$

$>100$ microwatt, < 1 milliwatt

125 micron singlemode, 9 micron core

2 meter fiber pigtail

$+4 \mathrm{~V}$ or $+/-2 \mathrm{~V}$, switch selectable

Survive transients of $100 \mathrm{~V}, 50 \mathrm{~ns}$

50 ohm nominal; >15 dB return loss

SMA female

SMA female; 50 ohm nominal

Single supply, specify voltage and current

Laser current: $1 \mathrm{~V} / 100 \mathrm{~mA}$

Photo Current: 1V/mA

\section{RECEIVER SPECIFICATION}

Optical Wavelength:

$1310 \mathrm{~nm}$ nominal

Fiber Type:

Connection:

Output Impedance:

output connector:

DC Power:

Monitor:

125 micron singlemode, 9 micron core

2 meter fiber pigtail

50 ohm nominal

SMA female

Specify voltage and current

Photo current: $1 \mathrm{~V} / \mathrm{mA}$ 
APPENDIX B

Bvaluation of Kaman 8ciences KPL100 Analog Fiber Optic Link

\section{INTRODUCTION}

Two midband analog fiber optic links were ordered from Kaman Sciences Corp (KSC) for evaluation. Although ordered in January, 1992, they were not delivered until August, 1992. Therefore it was impossible to install them on the HUNTERS TROPHY event. All of the data presented in this appendix were obtained in laboratory evaluations.

Appendix B-1 is the KSC technical description of the links. Appendix $B-2$ is the final specification for the links as delivered. The final specification deviates considerably from the initial technical description. The links have several very positive features:

1) Link gain of unity

2) Bandwidth extending to $900 \mathrm{MHz}$ or more

3) High sensitivity (0 - $100 \mathrm{mV}$ or $+/-50 \mathrm{mV})$

4) Packaged in standard NIM modules

5) Remote control and monitoring via RS-232 port

The negative characteristics are:

1) Dynamic range (measured) 28 to $34 \mathrm{~dB}$

2) Input VSWR greater than $1.7: 1$

3) Two to three times the cost of ortel 5522 


\section{EVALUATION}

Figure 1 shows network analyzer plots of response (bandwidth), and VSWR of the KSC links. Response is excellent, extending out beyond 1000MHz. Input VSWR, however, does not meet our needs, being greater than 1.7:1 over much of the range of interest. This equates to greater than $25 \%$ reflection of incoming signals. Link attenuation is much better than specification, actually showing a link gain of approximately two times.

Figure 2 is a plot of linearity taken in the unipolar mode. This plot compares the actual data with a fitted linear ideal. The units easily meet the linearity specification.

Figure 3 is an oscilloscope photograph of an input pulse superimposed on an output pulse after passage through the link. As can be seen, input and output track acceptably. There is a slight (1-2\%) droop seen in a 50 ns wide pulse.

Figure 4 is an oscilloscope photograph showing a multiple exposure of a full scale signal attenuated by $34 \mathrm{~dB}$ (2 $\mathrm{mV}$ applied to transmitter) and the associated link noise. This shows the signal-to-noise ratio at this input level to be slightly less than unity, which corresponds to a link dynamic range of approximately $32 \mathrm{~dB}(40: 1)$. The specification requires a minimum of $40 \mathrm{~dB}$ dynamic range. Performance in this area does not meet our requirements. 
CONCLUSION

Although the KSC links offer several unique features, the limited dynamic range and the poor input VSWR would both have to be significantly improved to meet current test requirements. The current pricing is also not competitive with other suppliers. 

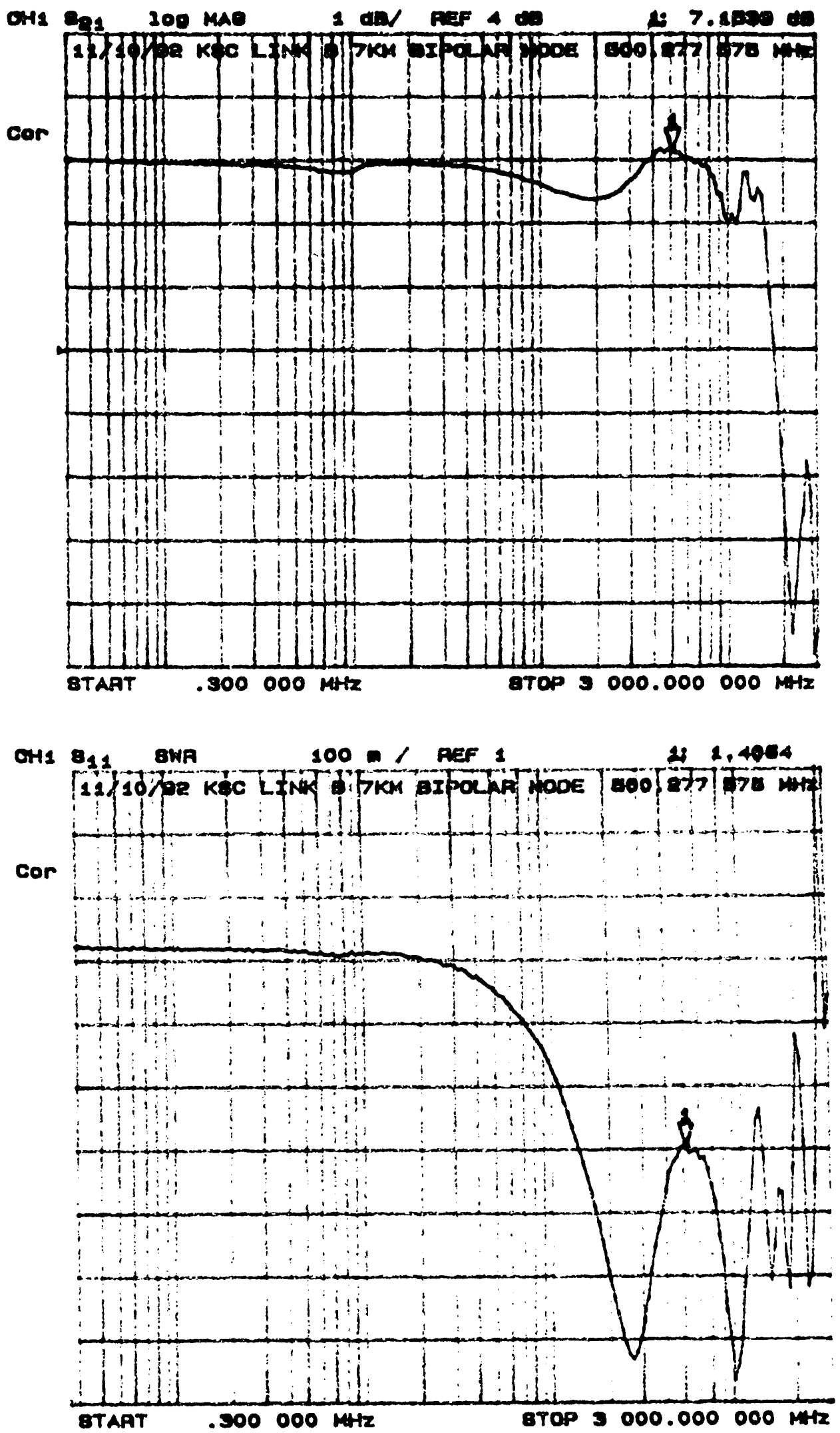

Fig. 1. Response, Attenuation and VSWR for KSC Model KPL100 Link 


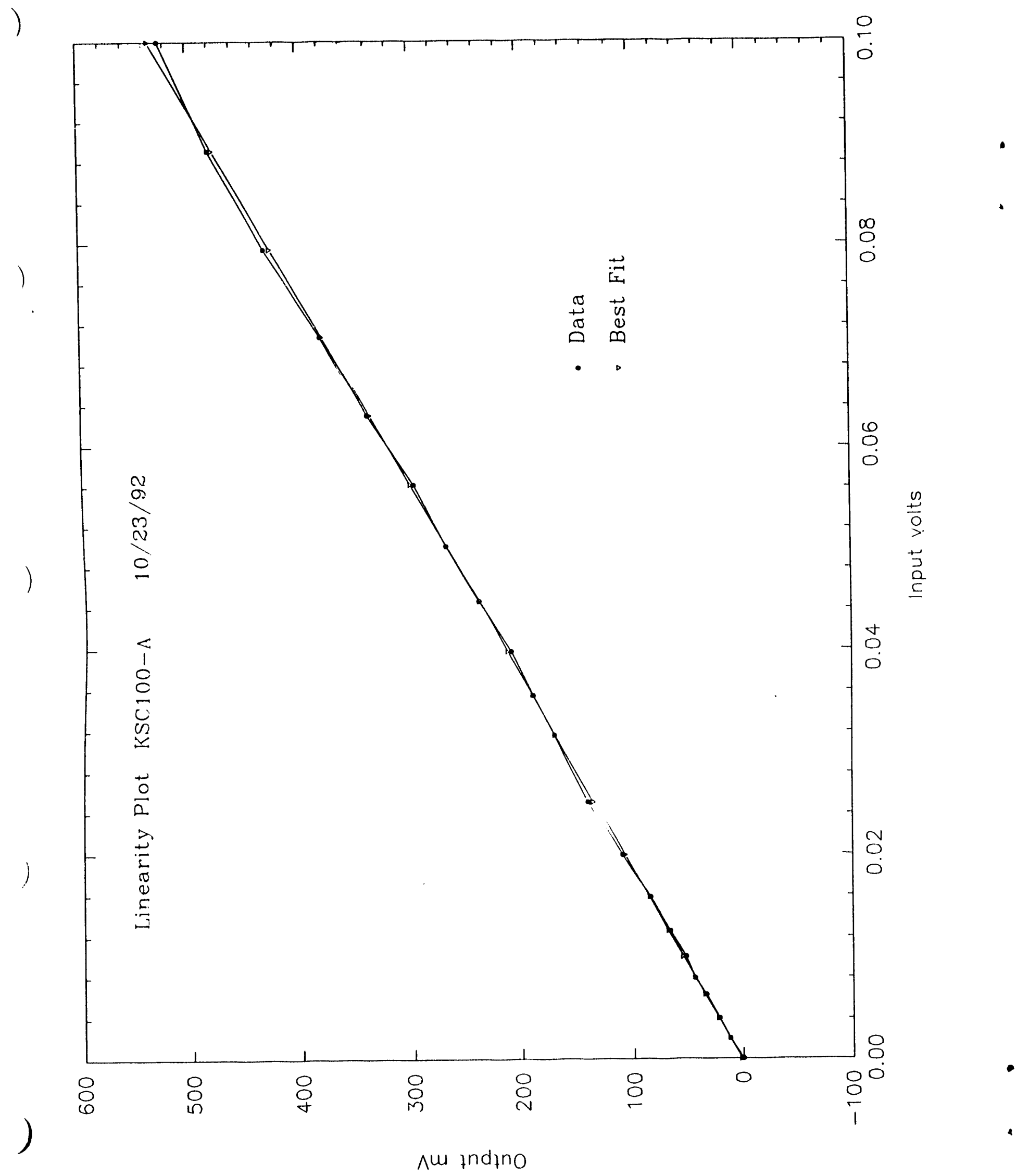

Fig. 2. Linearity Plot for KSC KPL100 Link 


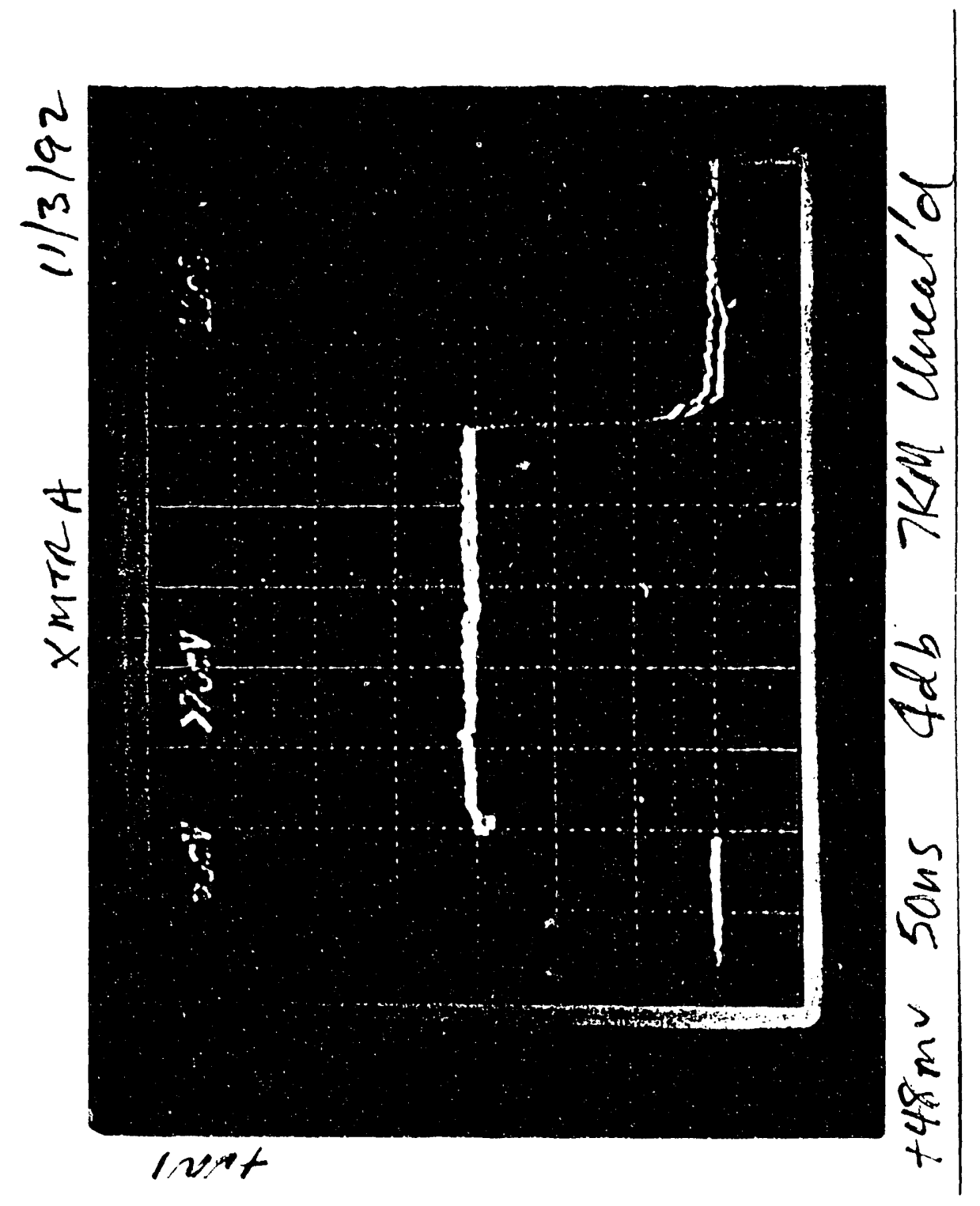

Fig. 3. Input/Output Overlay for KSC KPL100 Link 


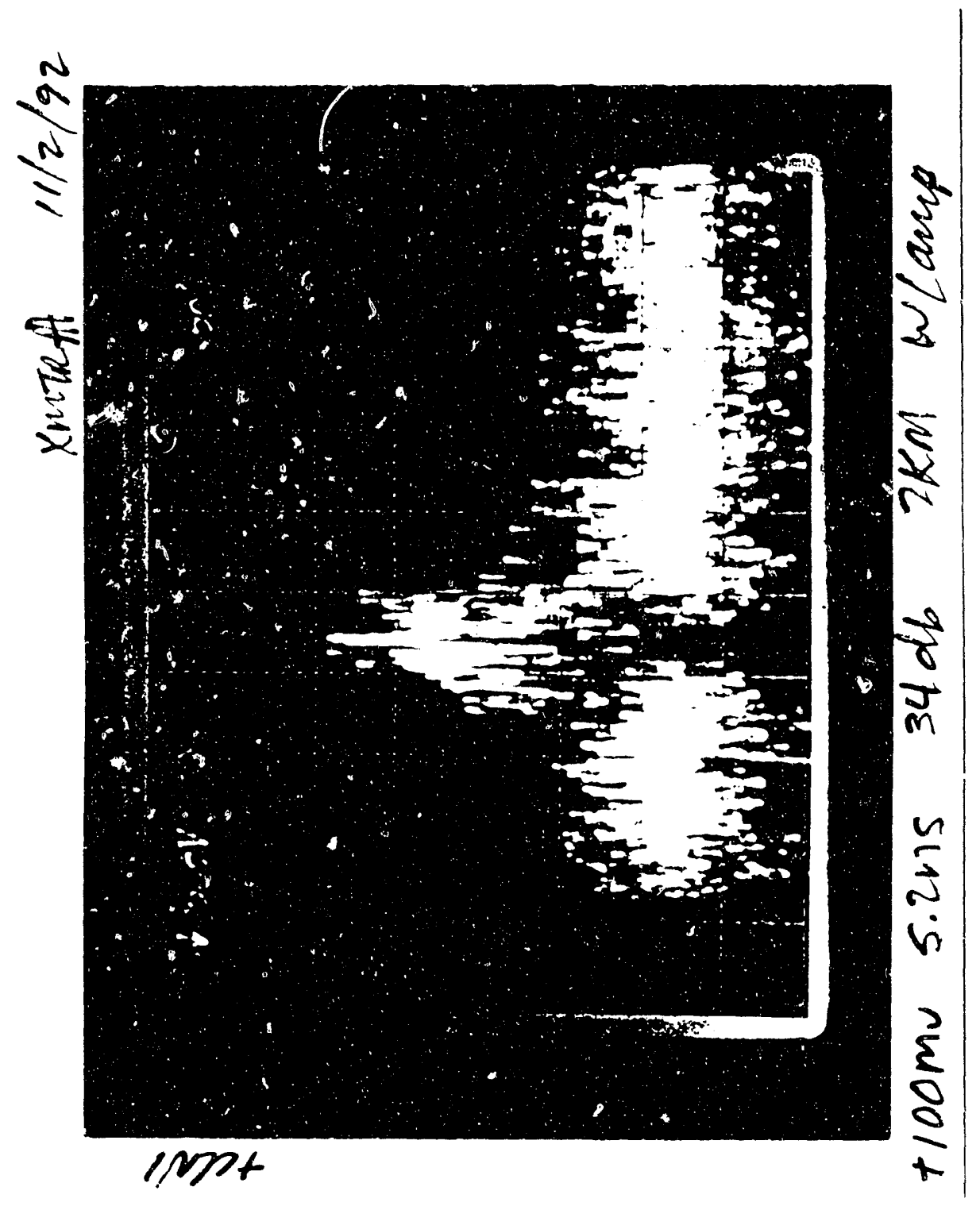

Fig. 4. Link Noise at -34 dB for KSC KPL100 Link (24) 


\section{APPENDIX B-1 \\ KPL-100LT/R Long Wavelength, Analog Telemetry Links Technical Module and System Description}

The KPL series of laser transmitters and receivers are specially designed for broadband, analog data acquisition systems. They incorporate system level features that are not found in any other telemetry link products. The KPL series offers complete individual channel control from a remote location (up to $10 \mathrm{~km}$ ) through an optical serial control link. Operations include setting full bias functions (CW, pulsed and s:art/stop modes), selecting input signal polarity settings, and performing 3-level amplitude and fast-rise step bandwidth calibration. The KPL series links provide the user with the capability of building a complete automated data acquisition system as shown in Figure 1. Both under- and above-ground operations are supported by two digital control link options. The links can be controlled from a dumb terminal with simple line commands. Alternatively, with custom software running on the user's system, it is possible to realize full automated calibration, link performance and trend analysis, and computer aided error detection and correction. A computer aided approach such as this can significantly reduce the amount of labor (and realize a real cost savings) involved in maintaining and operating a large data acquisition system.

Another unique feature of the KPL series is that the transmitters and receivers are individually compensated for a flat frequency response. This feature allows the inter-exchangability or "unmatched" use of any transmitter with any receiver, a big benefit for fielding applications.

Below is a summary of the specifications for Kaman's KPL links. The KPL series links meet the specifications as indicated in the SOW with the exception of the link gain stability as noted below. The operating transmitter environment is 0 to $50^{\circ} \mathrm{C}$ in 0 to $90 \%$ non-condensing humidity. The operating receiver environment is 15 to 35 ${ }^{\circ} \mathrm{C}$ in 0 to $90 \%$ non-condensing humidity. Storage temperature is -40 to $70{ }^{\circ} \mathrm{C}$ in 0 to $99 \%$ humidity.

The links can be operated in either a manual (front panel switches) or a remote (serial optical port) mode. A front panel and functional block diagram are shown in Figure 2. The units can be set to accept positive or negative $+4 \mathrm{~V}$ unipolar or $\pm 2 \mathrm{~V}$ bipolar input signals. The laser diode is p:otected from large signal input transients via the active devices incorporated in th: AFE section. The AFE may be replaced if damaged. The KPL link offers selectable pulse bias, triggered start/stop, or CW operation for maximum flexibility in system conficiration and timing. The bias trigger signals are TTL compatible. The pulse bias duration may be programmed through the serial control port. Tl.c front panel switches are locked out during remote operation and the remote settings are displayed on the front panel LED indicators.

The analog frequency response for a $7 \mathrm{~km}$ long link is $1 \mathrm{KHz}$ to $450 \mathrm{MHz}$ flat to \pm 0.5 $\mathrm{dB}$. The transmitter input and receiver output impedance is $50 \Omega$ with a link loss 
less than $20 \mathrm{~dB}$ non-inverting. The link gain stability is held to less than $\pm 1 \mathrm{~dB}$ over the full 0 to $50^{\circ} \mathrm{C}$ operating temperature range. Short term, 1 hour, stability in the 15 to $40^{\circ} \mathrm{C}$ (transmitter)temperature range of $\pm 0.25 \mathrm{~dB}$ is presently guaranteed. We are working to achieve a design goal of $\pm 0.1 \mathrm{~dB}$ stability. Long term, 48 hour, stability is $\pm 0.4 \mathrm{~dB}$.

Signal pulse response will have a risetime $<800$ ps, overshoot $<5 \%$, preshoot $<2 \%$ and droop $<5 \%$ in $50 \mu \mathrm{s}$. The dynamic range is better than $40 \mathrm{~dB}$. The linearity is nominally better than $\pm 5 \%$. The three point amplitude calibration method may improve this specification. Specific details of system amplitude calibration methods and operation are available from Kaman. The internal step calibrator has an amplitude of $1 \mathrm{~V} \pm 1 \%$, risetime $<1$ ns, overshoot $<3 \%$, and droop $<1 \%$. The step pulse may be triggered electrically from the front panel with a 3 to $15 \mathrm{~V}, 50 \Omega$ pulse or can be remotely enabled via the serial control link. The latter feature is valuable for complete independent uphole control, system diagnostics and link frequency characterization.

The units have full optical feedback and solid-state temperature control for optimal stability and laser lifetime. The laser has a typical emission wavelength of $1310 \mathrm{~nm}$ with a nominal single mode fiber output power of $1 \mathrm{~mW}$. The lasers are hermetically sealed for high reliability and long ( $>5000$ hour) operation life. Laser and photodiode current monitors are provided on the rear of the transmitter unit.

Calibration and remote control are accomplished through the remote optical serial link. The KPL module is designed to be either stand alone, daisy chained along the serial link or configured as an end node in a star-like network (Figure 3). Each module only responds to its unique ID number or an ALL-RESPOND control situation. Up to 128 modules may be individually addressed on one serial link. The serial commands may be issued from any RS-232C type port. A serial electrical-tooptical converter is required for KPL operation. The KPC-LT/R is a $7 \mathrm{~km}$ digital link with a STAR-type breakout multiplexer that can control up to 8 KPL modules (16 channels). It is fielded as shown in Figure 1.

The KPL-100LT transmitter and KPL-100LR receiver module are in a triple wide NTM format that contains two link channels. Up to four KPL modules (8 telemetry channels) may be configured in a 19" rack that contains the DC power supply. A diagram of the rack unit is shown in Figure 4. The power requirements of the KPL100LT are $-15 \mathrm{~V}(300 \mathrm{~mA}),-5 \mathrm{~V}(100 \mathrm{~mA}),+5 \mathrm{~V}(5 \mathrm{~A})$ and $+15 \mathrm{~V}(300 \mathrm{~mA})$. The power requirement of the 2-channel KPL-100LR is $+15 \mathrm{~V}(500 \mathrm{~mA})$. The rack and power supply for the transmitters (KPL.-PST) operates from $110 \mathrm{VAC}$ at $2 \mathrm{~A}$ and the rack and power supply for the receivers (KPL-PSR) operates from $110 \mathrm{VAC}$ at $0.4 \mathrm{~A}$. 


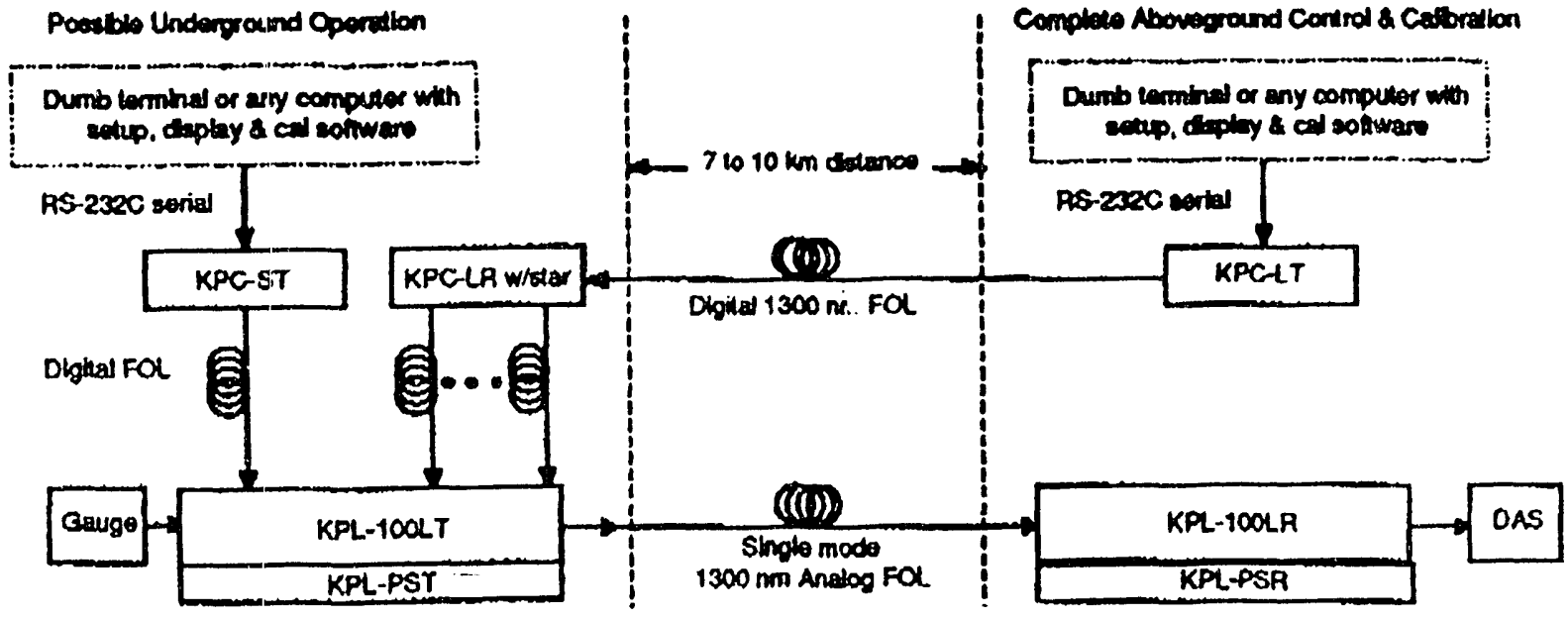

Figure 1. KPL series system operation.

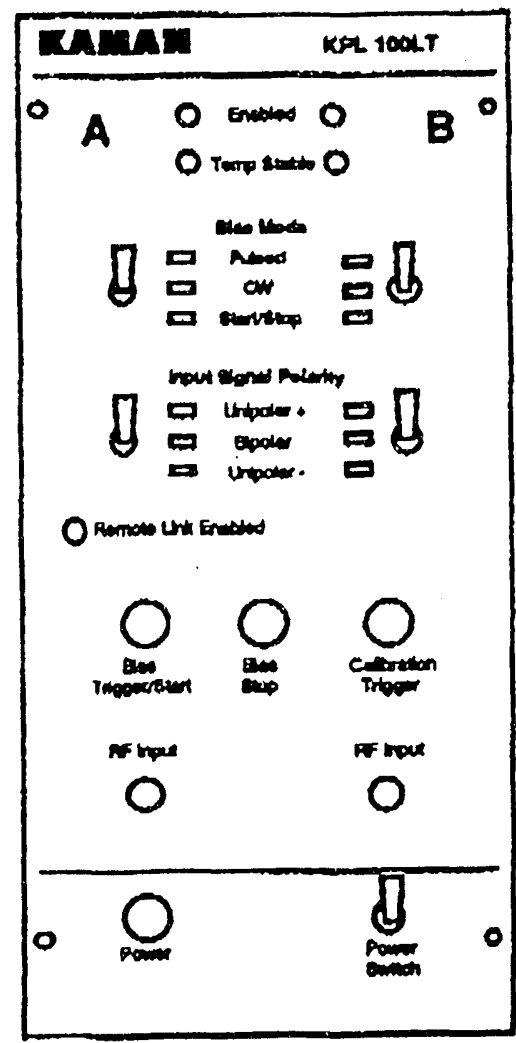

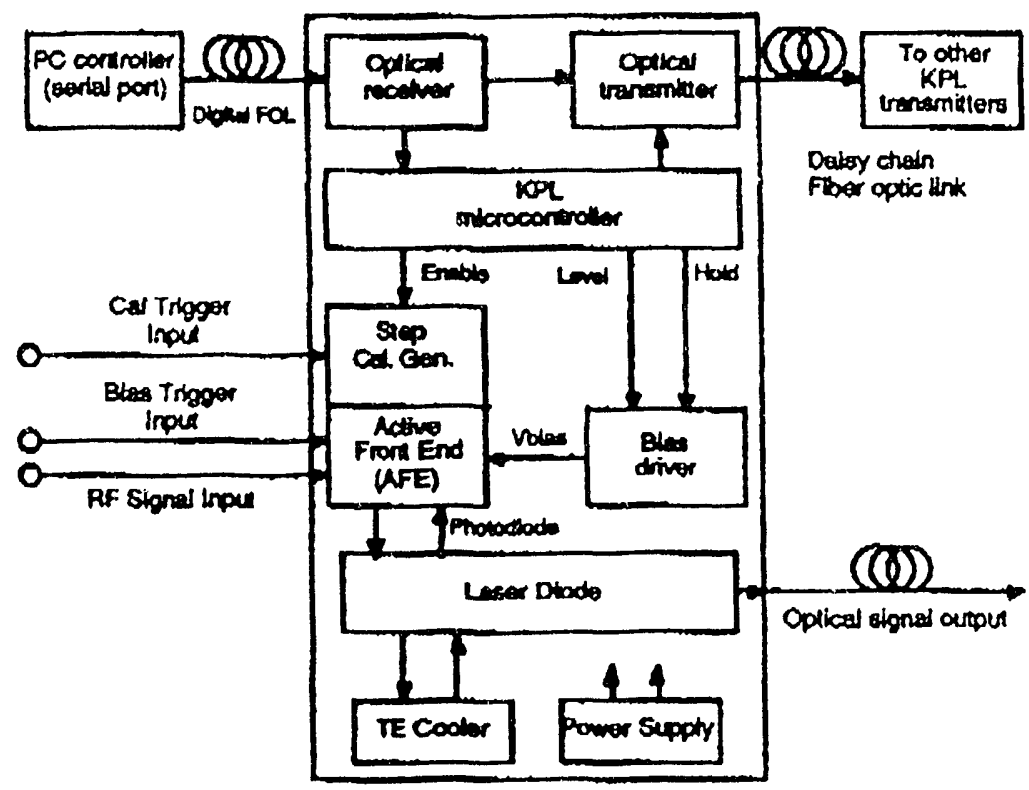

Figure 2. KPL series telemetry link. 

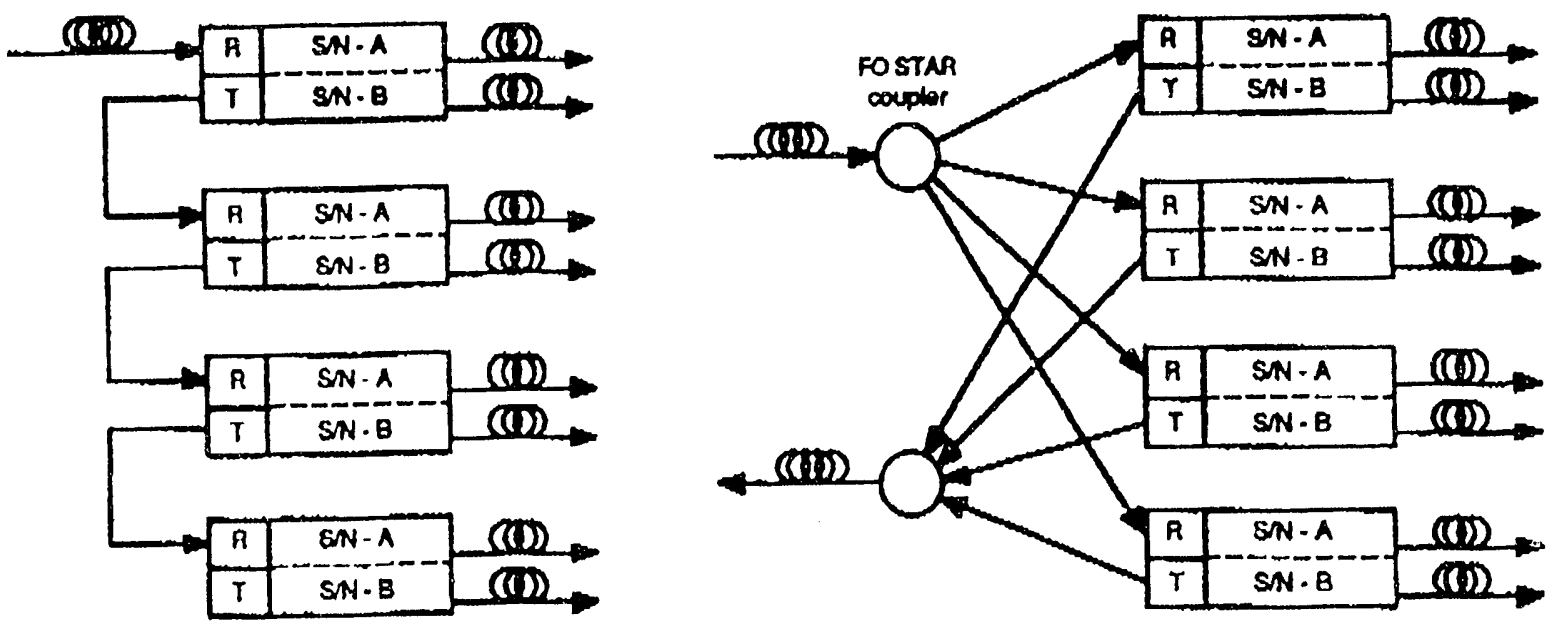

Figure 3. KPL serial optical control link configurations.

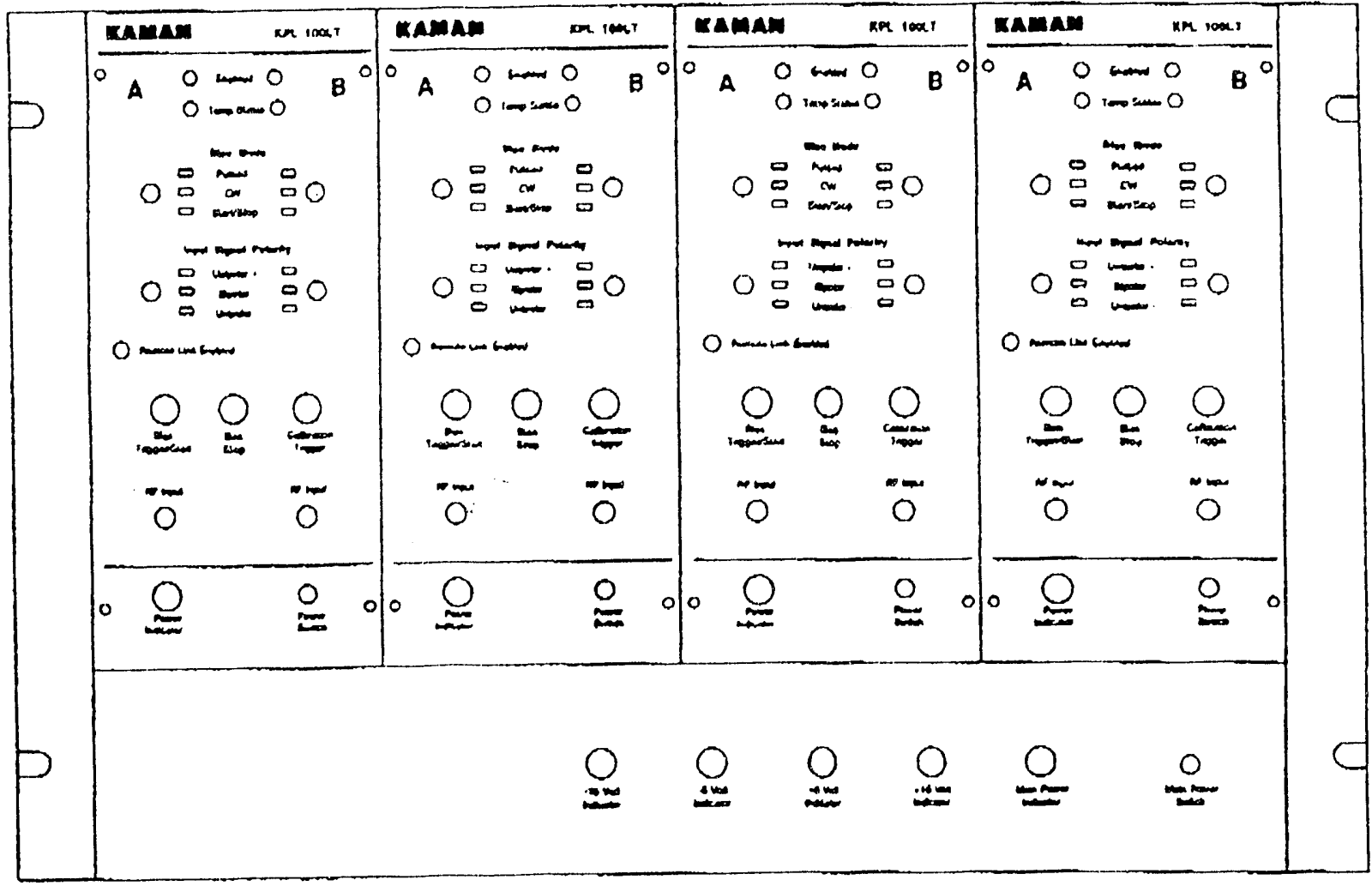

Figure 4. Rack configuration of 8 channel KPL telemetry links. 
Data Sheet *

$8 / 12 / 1992$
SPECIFICATION FOR KPL100LT/R ANALOG FIBER OPTIC TELEMETRY LINK

This analog fiber optic link is for transmitting high speed unipolar or bipolar transient data over greater than $7 \mathrm{~km}$ of low loss 1300 nanometer optical fiber. The link consists of a small low power laser transmitter and mating receiver.

Link Length:

$7 \mathrm{~km}$ typical (Measurements made at $9 \mathrm{~km}$ )

Optical Wavelength:

$1310 \mathrm{~nm}+/-30 \mathrm{~nm}$

Fiber Type:

$125 \mu \mathrm{m}$ singlemode, $9 \mu \mathrm{m}$ core

Connection:

$>2 \mathrm{~m}$ fiber pigtail (transmitter \& receiver)

Link Gain:

$>0 \mathrm{~dB}(1: 1)$ non-inverting electrical input to output

Frequency Response:

$5 \mathrm{KHz}$ to $900 \mathrm{MHz}$ flat to $+/-0.5 \mathrm{~dB}$

$5 \mathrm{KHz}$ to $1.7 \mathrm{GHz}, 3 \mathrm{~dB}$ Bandwidth

Pulse Response:

Response to a step-like input of $<200$ ps first transition duration shall be:

$\begin{array}{ll}\text { Risetime: } & <400 \mathrm{ps} \\ \text { Overshoot \& Ringing: } & <5 \% \\ \text { Preshoot : } & <5 \% \\ \text { Droop: } & <5 \% \text { in } 10 \mu \mathrm{s}\end{array}$

Linearity: $\quad+/-5 \%$ for all frequencies in the pass band

Dynamic Range: $\quad$ Greater than $46 \mathrm{~dB}$ (200:1) [including high sensitivity input and link gain greater than zerol

Stability: $\quad$ Link gain shall be stable to $+/-1 \mathrm{~dB}$

Short term stability at $25^{\circ} \mathrm{C}$ shall be:

1 hr. term: $\quad+/-0.5 \mathrm{~dB}$

24 hr. term: $\quad+/-0.5 \mathrm{~dB}$

Electrical

Input: Voltage: $\quad+0.1 \mathrm{~V}$ or $+/-0.05 \mathrm{~V}$, switch selectable

Protection: $\quad$ Survive transients of $100 \mathrm{~V}, 50 \mathrm{~ns}$

Impedance: $\quad 50 \Omega$ nominal; $>10 \mathrm{~dB}$ return loss

Connector: SMA female

"Specifications subject to change without notice 
SPECIFICATION FOR KPL100LT/R

Electrical

Output: Impedance:

Voltage: $\quad+0.1 \mathrm{~V}$ or $+/-0.05 \mathrm{~V}$, switch selectable

Connector: $\quad$ SMA female

XMTR: Optical pwr.: $>100 \mu \dot{W}$

DC power: $\quad-24 \mathrm{~V}(500 \mathrm{~mA}),+12 \mathrm{~V}(500 \mathrm{~mA})$ and $+24 \mathrm{~V}(800 \mathrm{~mA})$

Temp: $\quad 0$ to $50^{\circ} \mathrm{C}$

Humidity: $\quad 0$ to $90 \%$, non-condensing

RCVR: DC Power: $\quad+24 \mathrm{~V}(500 \mathrm{~mA}),-24 \mathrm{~V}(300 \mathrm{~mA})$

Temp: $\quad 15$ to $30^{\circ} \mathrm{C}$

Humidity: $\quad 0$ to $90 \%$, non-condensing

Storage Environment: Temperature: -40 to $70^{\circ} \mathrm{C}$

Humidity: 0 to $90 \%$, non-condensing

Lifetime:

$>5000$ hours.

Calibration:
The link shall have a built-in calibration puise generator to allow link gain to be determined to within $+/-2.0 \%$. This signal shall consist of a step-like pulse with the following specifications:

$\begin{array}{ll}\text { Amplitude: } & 0.1 \mathrm{~V}+/-2.0 \% \\ \text { Width: } & 100 \mathrm{~ns} \text { nominal } \\ \text { Risetime: } & <1.0 \mathrm{~ns} \\ \text { Overshoot: } & <3.0 \% \\ \text { Droop: } & <3.0 \% \\ \text { Delay: } & <40 \mathrm{~ns} \text { (trig in to pulse out) }\end{array}$

Trigger input: SMA female; $50 \mathrm{ohm}$ nominal Amplitude: 3 to 15 volts into $50 \mathrm{ohms}$ Width: $>50 \mathrm{~ns}$

Risetime: $<10$ ns 


\section{APPENDIX C}

\section{Evaluation of Laser Diode LDAT2200 Analog Fiber Optic Iink}

\section{INTRODUCTION}

Laser Diode Inc. (LDI), located in Edison, NJ, was one of the suggested suppliers when the midband fiber optic link specification went out for bid in November, 1991. After deciding not to submit a bid in response to the Request for Quote, LDI contacted us in March, 1992 and expressed a desire to supply links with specifications similar to those which we had requested.

An order was placed in late April for two units with delivery requested in June, 1992. The units were actually received in mid July. Since channel assignments for the DNA measurements on HUNTERS TROPHY had already been made, it was decided to use the LDI links to support an add-on fiber optic multiplex experiment being fielded by Sandia Laboratories. The two links were subjected to a subset of the normal characterization process prior to the event and the evaluation completed after the event. Good data was received via both links on the event.

Appendix $\mathrm{C}-1$ is the operating instructions and specifications for the LDAT-2200 data links as provided by LDI. With the exception of the lack of an internal 
calibrator, the units are compatible with most of the desired specifications.

\section{EVALUATION}

Figure 1 is a network analyzer plot of the frequency response (bandwidth) of one of the LDI model 2200 links. The specification calls for a flat response $(+/-0.5 \mathrm{~dB})$ from $1 \mathrm{KHz}$ to $500 \mathrm{MHz}$. With the exception of a dip at $1.5 \mathrm{MHz}$ and some peaking at $200 \mathrm{MHz}$, the units meet the specification. The deviations are small and are not considered to be significant. The plot also shows the link attenuation to be nominally $7 \mathrm{~dB}$. This is considerably better than the specified value of less than $20 \mathrm{~dB}$.

Figure 2 ia a network analyzer plot of VSWR versus frequency. The values range from 1.01 (almost perfect) over most of the range to 1.3 at the low frequency extreme. This easily meets specification and is the best impedance match that we've seen.

Figure 3 is a plot of linearity, typical for both units. The plot shows the measured output versus input voltage overlaid with a linear ideal. The specification calls for a maximum deviation of $+/-5 \%$ from a straight line fitted to the data. The units are well within that specification.

Figure 4 is an oscilloscope photograph of an input pulse superimposed on an output pulse after passage through the 
link. As can be seen, the pulses track reasonably well. However, there is about $15 \%$ overshoot on the leading edge followed by significant ringing at about $1000 \mathrm{MHz}$. There is also some apparent tailing where the output pulse returns to baseline.

Figure 5 is an oscilloscope photograph showing a multiple exposure of a full scale signal attenuated by $40 \mathrm{~dB}$ $(20 \mathrm{mV}$ input to the transmitter) and the associated link noise. This shows the signal-to-noise ratio at this input level to be approximately $0.7: 1$, which corresponds to a link dynamic range of $37 \mathrm{~dB}(70: 1)$. This fails to meet specification and is greatly below the desired range of 46 $\mathrm{dB}$.

\section{CONCLUSION}

The current LDI links are a considerable improvement over those previously evaluated (in 1989). The attenuation and VSWR are particularly attractive. However, the limited dynamic range would have to be significantly improved to meet test requirements. The problems of overshoot and ringing would also have to be resolved. Pricing is about twice that of the ortel 5522, but volume purchases would probably bring them in line. LDI has the potential to be a good additional supplier. 


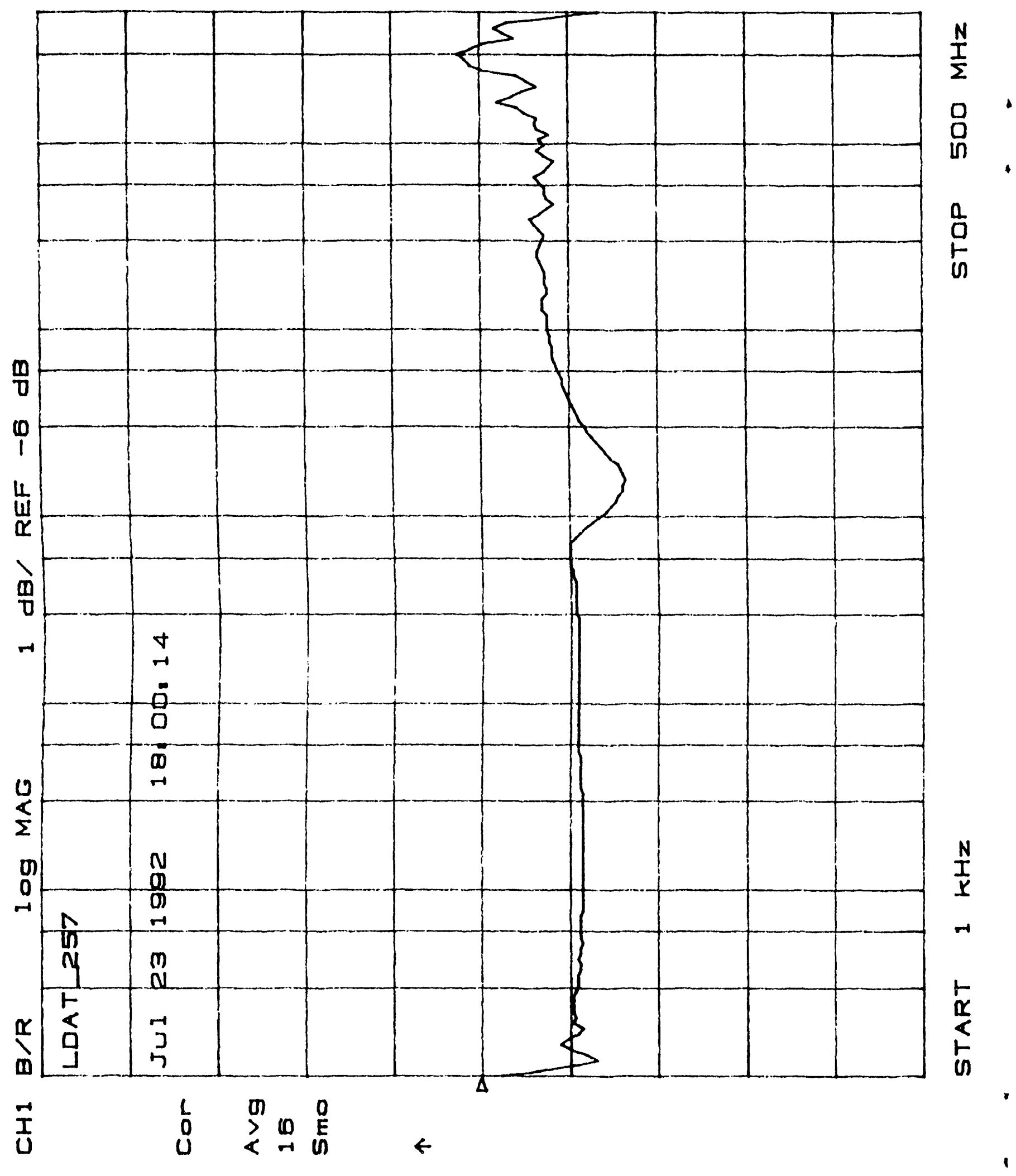

Fig. 1. Response and Attenuation of LDI LDAT2200 Link 


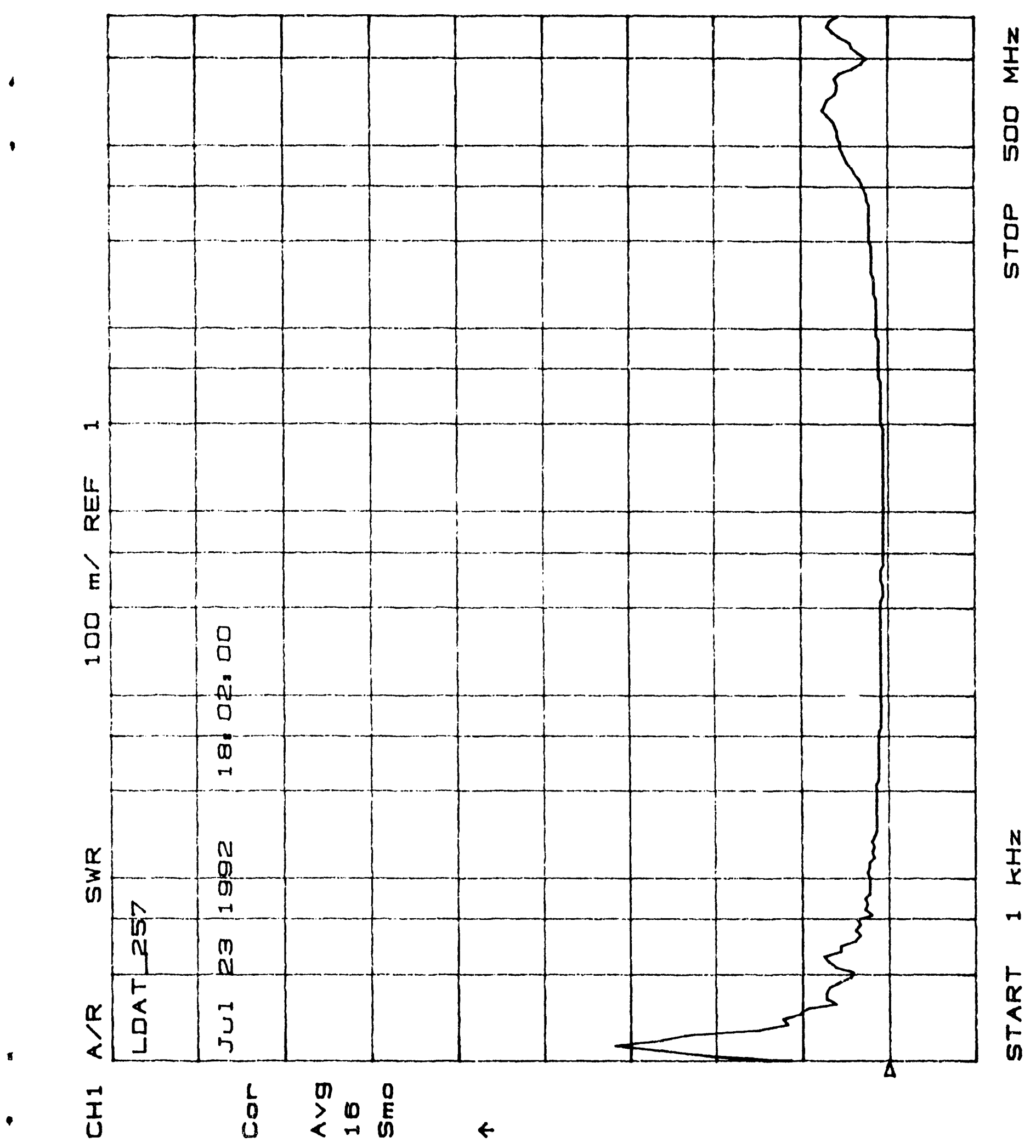

Fig. 2. VSWR of LDI LDAT2200 Link 


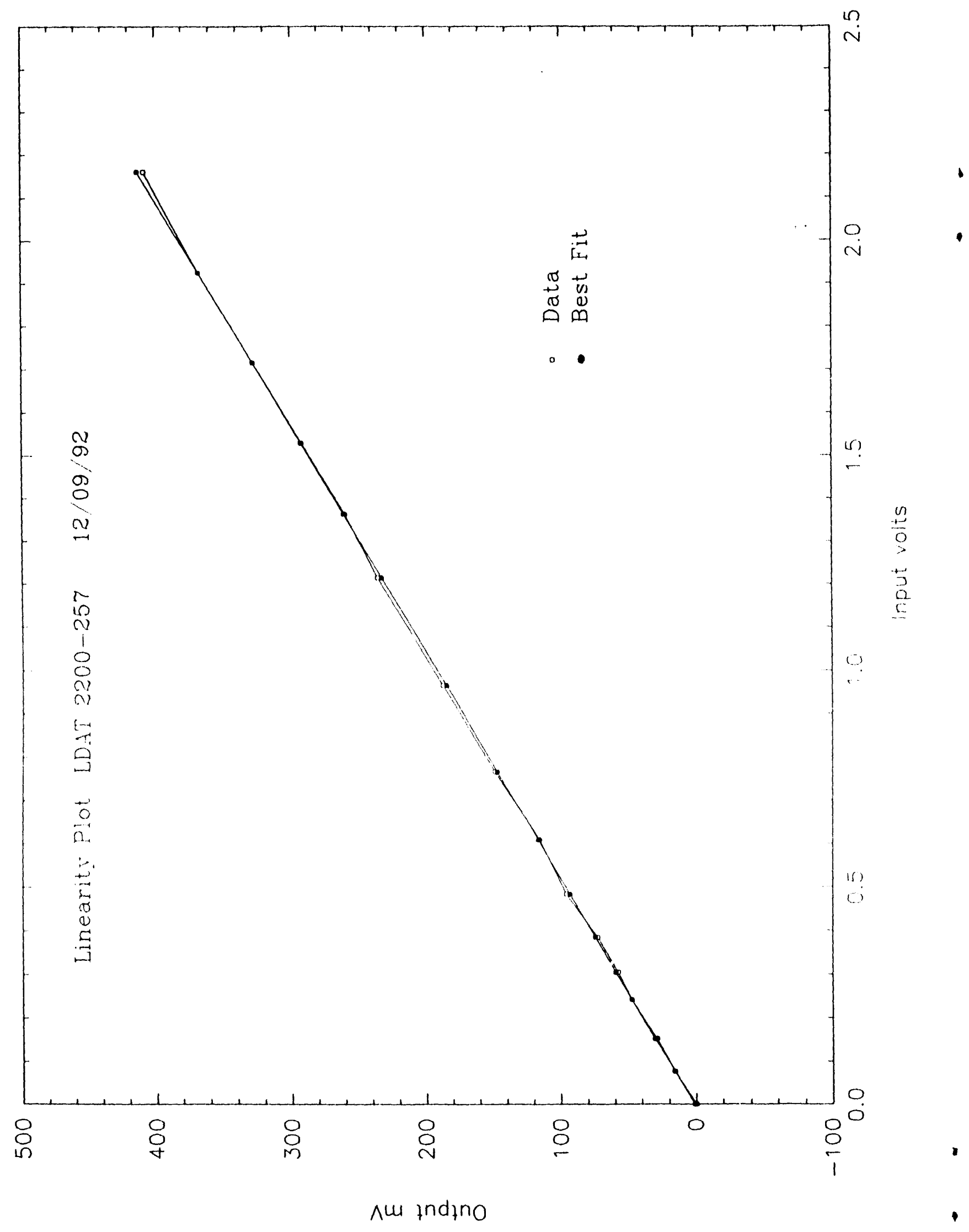

Fig. 3. Linearity Plot for LDI LDAT2200 Link 


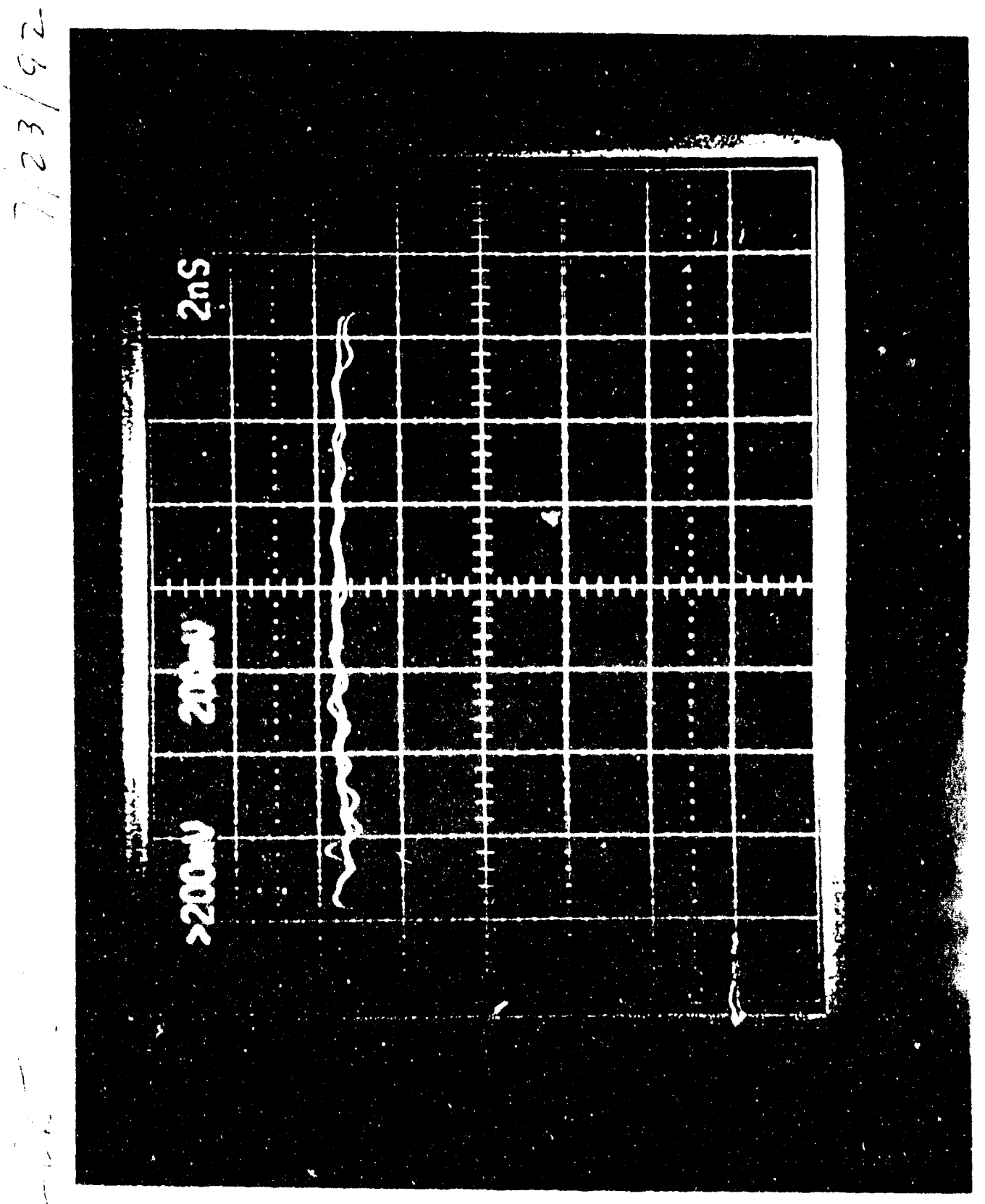

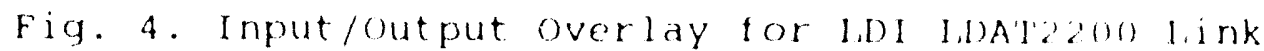
$(3 \%)$ 


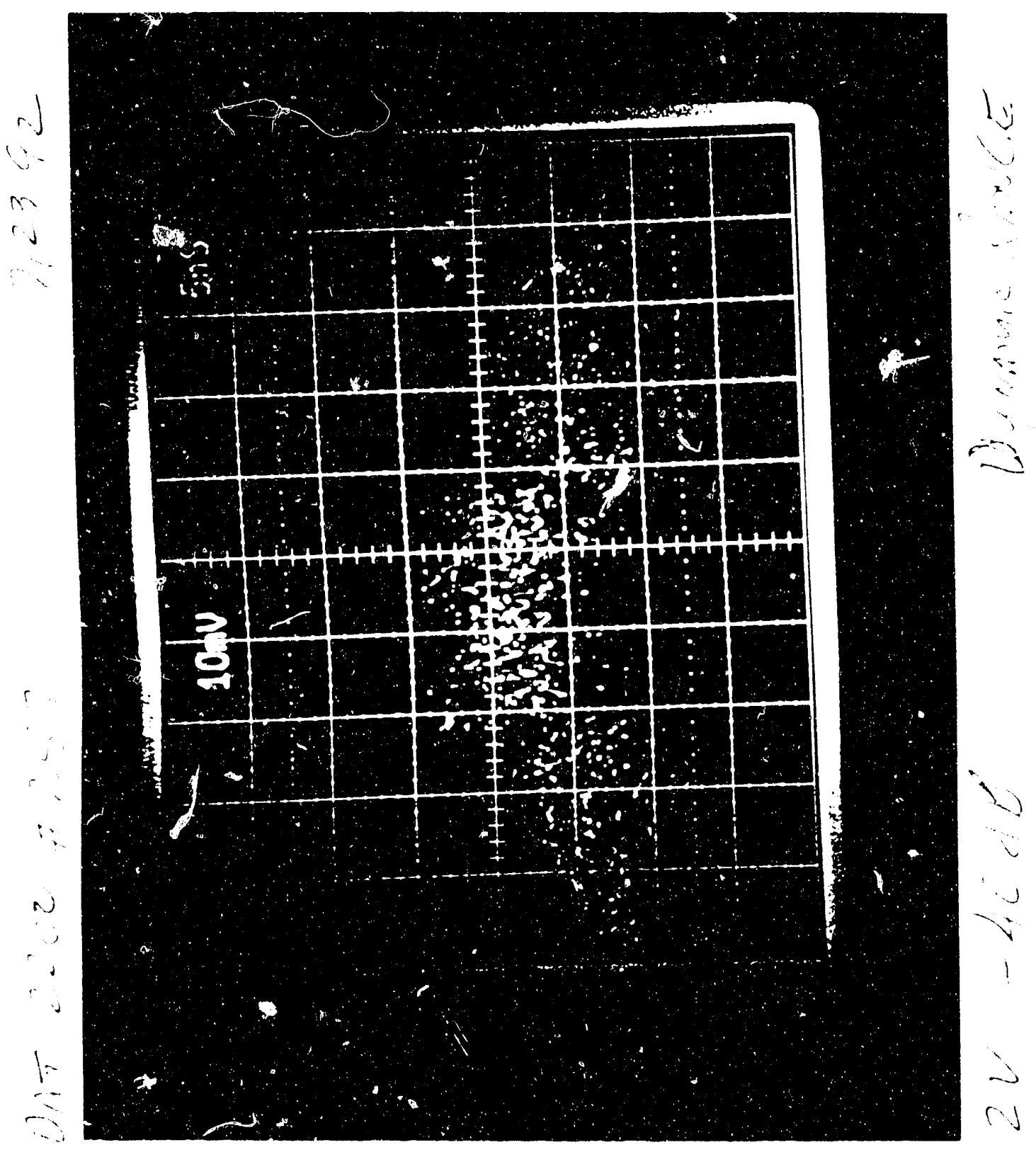

Fig. 5. Link Noise at $-40 \mathrm{~dB}$ for LDI LDAT2200 Link (38) 


\section{APPENDIX $\mathrm{C}-1$ \\ LASER DIODE INC. \\ ANALOG TRANSMITTER - MODEL "LDAT-2200" \\ OPERATING IINSTRUCTIONS}

\section{ELECTRICAL CONNECTIONS}

POWER SUPPLY

The transmitter requires a $-5+/-5 z$ volt, 1.2 amp well regulated power supply. The negative lead is connected to the -5 volt terminal. The positive lead is connected to the common terminal as shown in Fig. 1. The nominal current requirement for a chassis temperature of $25 \mathrm{C}$ is $100-200 \mathrm{~mA}$. As the chassis temperature increases, current requirements will increase up to a maximum of 1.2 amps as demanded by the thermoelectric cooler.

RF INPUT

The RF input is capacitively coupled through the 50 ohm SMA connector. The RF analog input amplitude should be externally adjusted not to exceed a $50 \%$ modulation depth for minimum distortion in the light output. Digital inputs (with $50 \%$ duty cycle) may also be accommodated with the same input signal limitations.

\section{ADJUSTMENTS}

\section{LIGHT OUTPUT POWER}

The transmitter is normally supplied with the light output from the laser adjusted at the midpoint of the linear region. For analog or digital modulation with a 508 duty cycle, no adjustments are necessary.

\section{THERMOELECTRIC COOLER}

The peltier element increases laser reliability by limiting laser temperature to $25 \mathrm{C}$.

As the temperature increases, heatsinking requirements to the trinsmitter also increase due to the increased power dissipation rt.uirements of the cooler. Consequently, adequate heatsinking is imperative in order to realize a case temperature approaching the ambient at high temperatures.

The cooler circuitry is factory set and contains no user adjustments. 
PAGE 2

\section{ALARM OUTPUT}

An electrical alarm output and a visual LED indicator are provided that switch in the event the laser bias current increases beyond a pre-determined level $(+20 \%)$. The purpose of such a signal is to sense changes in circuit or environmental conditions that usually occur days before the transmitter becomes totally inoperative or seriously degraded. Three of the most probable mechanisms that can trigger the alarm are:

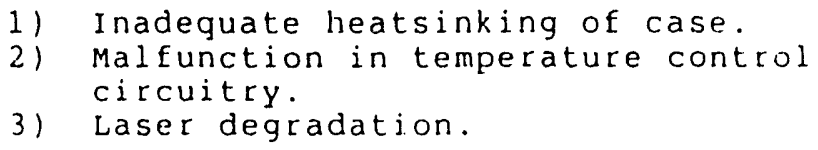

1) Inadequate heatsinking of case.

2) Malfunction in temperature control circuitry.

3) Laser degradation.

The alarm output interface circuit provides a TTL level compatible output drive when pulled up to an external $+5 v$ supply.

Operation is similar to a conventional open collector output. For a TTL-compatible alarm an external pull-up resistor to 5 VDC is required. Under normal operating conditions the alarmoutput is high $(+5 \mathrm{~V})$, when the laser operating current exceeds the alarm set point the alarm output is pulled low (approximately zero volts).

The optimum value of pull-up resistance is approximately 220 OHMS to +5 VDC. Higher values may be used, however the alarm-on-state voltage may go slightly negative as the pull-up resistance is increased or as the pull-up voltage is increased.

Maximum alarm output sink current is $30 \mathrm{~mA}$.

The alarm set point is factory adjusted for $20 \%$ above normal operating laser bias and normally does not require adjustment.

$02 / 90$ 


\section{LASER DIODE INC. \\ ANALOG RECEIVER - MODEL "LDAR-2200" \\ OPERATING INSTRUCTIONS}

\section{DESCRIPTION}

The model "LDAR-2200" long wavelength receiver is designed around a custom-built PIN module using a GaInAs photodiode. The optical signal is coupled to the photodiode via a 9 um core fiber pigtail.

The optical signal received by the PIN is converted to an electrical signal. The signal is then amplified and brought out to the RF output jack on the RX module.

\section{ELECTRICAL CONNECTIONS}

\section{POWER SUPPLY}

The receiver requires -15 volt $(+/-5 \%),+15$ volt $(+/-5 \circ), 0.5$ amp well regulated power supplies. The negative lead is connected to the -15 volt terminal. The positive lead is connected to the +

15 volt terminal as shown in Fig. 1.

RF OUTPUT

The RF output is capacitively coupled tirough the 50 ohm SMA connector.

\section{ADJUSTMEN'T'S}

The receiver contains no user adjustments.

\section{ALARM OUTPUT}

An electrical alarm output is provided that will switch in the event detected optical signal decreases below a pre-determined level. The purpose of such a signal is to sense changes in optical signal levels that will degrade signal quality. Two of the most probable mechanisms that can trigger the alarm are:

1) Loss of optical signal - break in optical path, laser degradation, or loss of power to optical transmitter.

2) Excessive connector loss.

When an alarm condition occurs the LED will switch on. During a non-alarm (normal operation) state the LED will switch off.

Typically, the alarm will trigger when the link losses exceed approximately 10 to $15 \mathrm{~dB}$ of optical loss. The alarm is fartory set and normally does not requile adjustment.

$02 / 90$

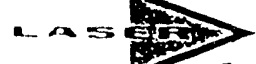




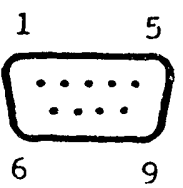

MODEL LDAL-2200

TRANSMITTER PINOUT

\begin{tabular}{|c|c|}
\hline PIN \# & DESCRIPTION \\
\hline 1 & -5 VDC \\
\hline 2 & GROUND \\
\hline 3 & ALARM \\
\hline 4 & NC \\
\hline 5 & GROUND \\
\hline 6 & GROUND \\
\hline 7 & GROUND \\
\hline 8 & GROUND \\
\hline 9 & GROUND \\
\hline G & GR \\
\hline &
\end{tabular}

FIGURE 1. PINOUT DIAGRAM
RECEIVER PINOUT

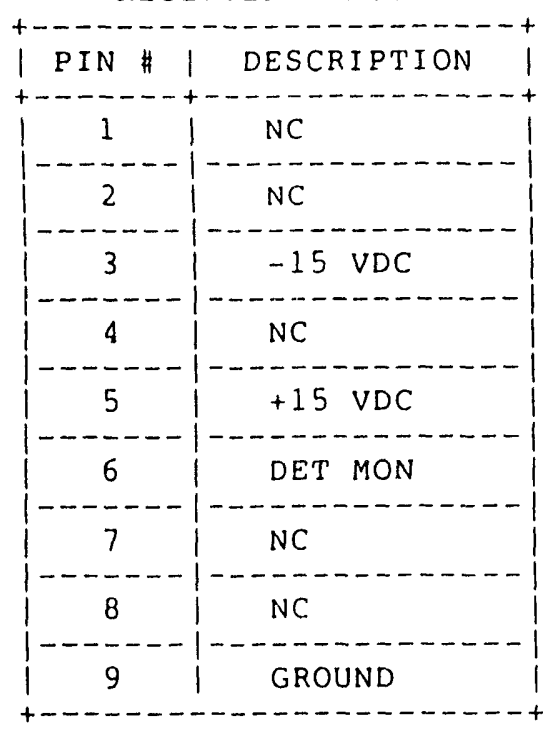

$02 / 90$

$-\infty=$ 


\section{DISTRIBUTION}

11 FCDNA/CEIC

Attn: Debby E. Roe, Lt. USN

Mike Archuleta

Larry Ashbaugh

George Lu

Ted Maxfield

Kiran Shah

Robert Shirky

William Shoup

Francis Stepaniak

Ajay Verma

Anil Verma

4420 Mitchell Road

North Las Vegas, NV 89031

3 Los Alamos National Laboratory

Attn: D. Bartram

M. Hockaday

T. Petersen

Division P-14, Mail Stop D410

Los Alamos, NM 87545

3 EG\&G Energy Measurements Group

Attn:

B. Betz

P. Breeding

D. Demings

Nevada Test Site

Mercury, NV 89023

1 Science Applications International Corp

Attn: $K$. Sites

3351 S. Highland Dr., Suite 206

Las Vegas, NV 89109

2 Ortel corp.

Attn: B. Cunningham

W. Moore

2015 W. Chestnut st.

Alhambra, CA 91803-1542

1 Kaman Sciences Corp.

Attn: J. Fanning

1500 Garden of the Gods Rd.

Colorado Springs, CO 80933

1 Laser Diode Inc.

Attn: H. Wojtunik

1130 Somerset $S t$.

New Brunswick, NJ 08901 


$\begin{array}{rll}1 & 9300 & \text { J. E. Powell } \\ 1 & 9301 & \text { J. D. Plimpton } \\ 1 & 9305 & \text { M. J. Navratil } \\ 1 & 9311 & \text { A. J. Chabai } \\ 1 & 9312 & \text { K. M. Glibert } \\ 1 & 9312 & \text { J. D. Weiss } \\ 1 & 9321 & \text { W. B. Boyer } \\ 1 & 9322 & \text { C. W. Cook } \\ 10 & 9322 & \text { G. J. Hansen } \\ 1 & 9322 & \text { E. S. Herrera } \\ 1 & 9322 & \text { R. G. Oliveira } \\ 1 & 9322 & \text { F. Salas } \\ 1 & 9323 & \text { G. L. Ogle } \\ 1 & 9323 & \text { B. C. Bedeaux } \\ 1 & 9323 & \text { D. C. Browne } \\ 1 & 9323 & \text { J. T. McIlmoyle } \\ 1 & 9323 & \text { P. L. Wehrman } \\ 1 & 9324 & \text { P. L. Nelson } \\ 1 & 9324 & \text { J. A. Chael } \\ 1 & 9324 & \text { R. Davis } \\ 1 & 9324 & \text { D. S. Nelson } \\ 1 & 9324 & \text { F. M. Raymond } \\ 1 & 9351 & \text { J. Hohlfelder } \\ 1 & 8523-2 & \text { Central Technical Files } \\ 5 & 7141 & \text { Technical Library } \\ 1 & 7151 & \text { Technical Publications } \\ 10 & 7613-2 & \text { Document Processing for DoE/OSTI }\end{array}$



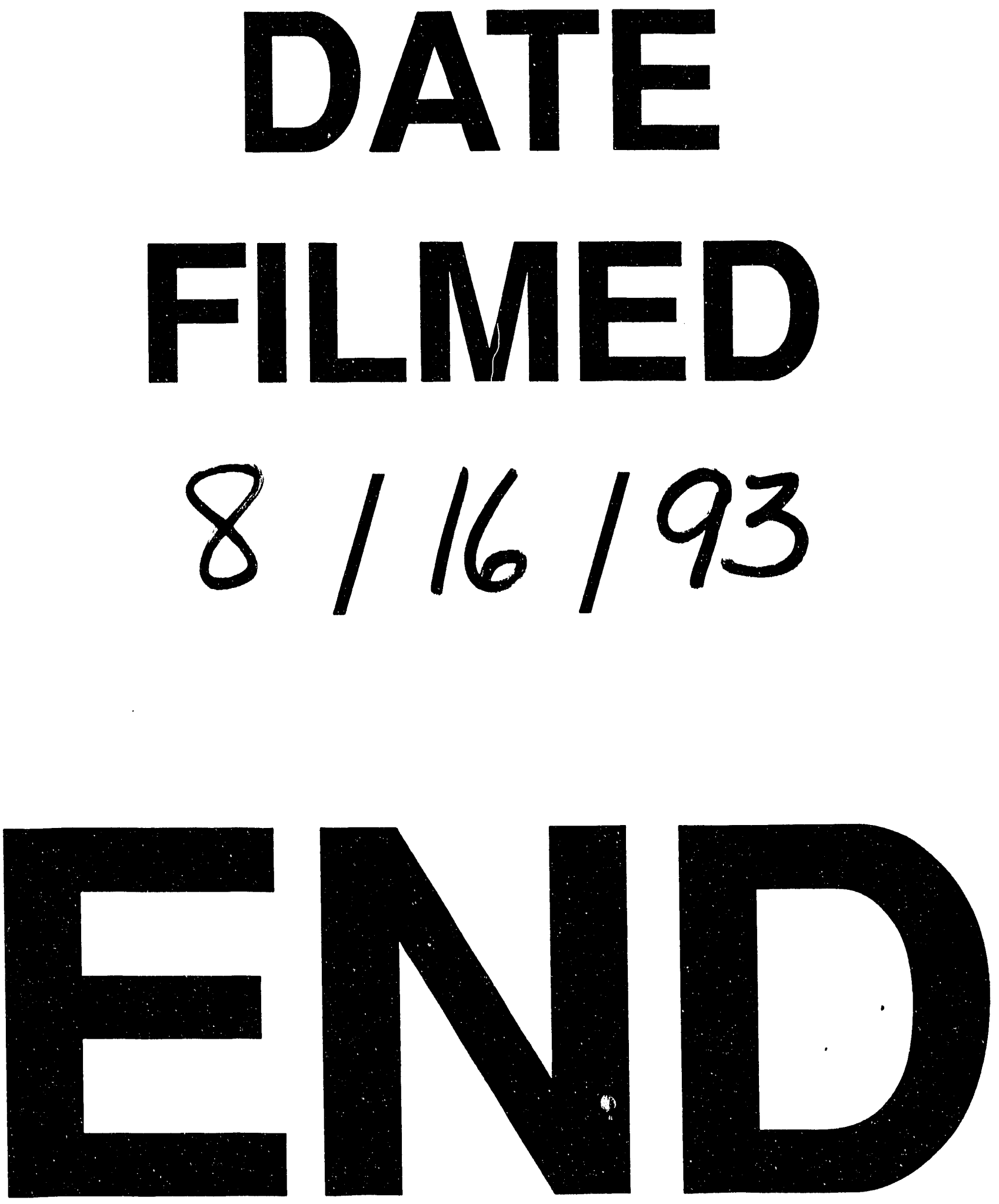
